NASA/TM-2006-214460
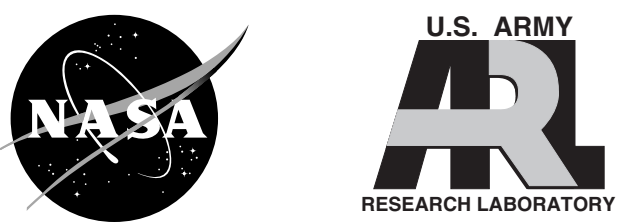

\title{
Evaluation of an Outer Loop Retrofit Architecture for Intelligent Turbofan Engine Thrust Control
}

Jonathan S. Litt

U.S. Army Research Laboratory, Glenn Research Center, Cleveland, Ohio

T. Shane Sowers

Analex Corporation, Brook Park, Ohio 


\section{NASA STI Program . . . in Profile}

Since its founding, NASA has been dedicated to the advancement of aeronautics and space science. The NASA Scientific and Technical Information (STI) program plays a key part in helping NASA maintain this important role.

The NASA STI Program operates under the auspices of the Agency Chief Information Officer. It collects, organizes, provides for archiving, and disseminates NASA's STI. The NASA STI program provides access to the NASA Aeronautics and Space Database and its public interface, the NASA Technical Reports Server, thus providing one of the largest collections of aeronautical and space science STI in the world. Results are published in both non-NASA channels and by NASA in the NASA STI Report Series, which includes the following report types:

- TECHNICAL PUBLICATION. Reports of completed research or a major significant phase of research that present the results of NASA programs and include extensive data or theoretical analysis. Includes compilations of significant scientific and technical data and information deemed to be of continuing reference value. NASA counterpart of peer-reviewed formal professional papers but has less stringent limitations on manuscript length and extent of graphic presentations.

- TECHNICAL MEMORANDUM. Scientific and technical findings that are preliminary or of specialized interest, e.g., quick release reports, working papers, and bibliographies that contain minimal annotation. Does not contain extensive analysis.

- CONTRACTOR REPORT. Scientific and technical findings by NASA-sponsored contractors and grantees.
- CONFERENCE PUBLICATION. Collected papers from scientific and technical conferences, symposia, seminars, or other meetings sponsored or cosponsored by NASA.

- SPECIAL PUBLICATION. Scientific, technical, or historical information from NASA programs, projects, and missions, often concerned with subjects having substantial public interest.

- TECHNICAL TRANSLATION. Englishlanguage translations of foreign scientific and technical material pertinent to NASA's mission.

Specialized services also include creating custom thesauri, building customized databases, organizing and publishing research results.

For more information about the NASA STI program, see the following:

- Access the NASA STI program home page at http://www.sti.nasa.gov

- E-mail your question via the Internet to help@sti.nasa.gov

- Fax your question to the NASA STI Help Desk at 301-621-0134

- Telephone the NASA STI Help Desk at 301-621-0390

- Write to:

NASA STI Help Desk

NASA Center for AeroSpace Information 7121 Standard Drive Hanover, MD 21076-1320 
NASA/TM-2006-214460

ARL-TR-3880
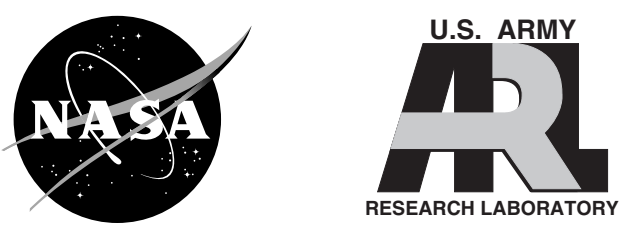

\section{Evaluation of an Outer Loop Retrofit Architecture for Intelligent Turbofan Engine Thrust Control}

Jonathan S. Litt

U.S. Army Research Laboratory, Glenn Research Center, Cleveland, Ohio

T. Shane Sowers

Analex Corporation, Brook Park, Ohio

Prepared for the

42nd Joint Propulsion Conference and Exhibit

cosponsored by the AIAA, ASME, SAE, and ASEE

Sacramento, California, July 9-12, 2006

National Aeronautics and

Space Administration

Glenn Research Center

Cleveland, Ohio 44135 


\section{Acknowledgments}

The authors gratefully acknowledge Sanjay Garg's significant role in the development of the overall retrofit architecture, Tak Kobayashi's contribution of the FADEC-like controller and piecewise linear model, and his invaluable assistance, and Don Simon's substantiating investigations into the use of common SVD-based tuners across the flight envelope.

This research was supported by Propulsion 21.

Level of Review: This material has been technically reviewed by technical management.

Available from

NASA Center for Aerospace Information 7121 Standard Drive

Hanover, MD 21076-1320
National Technical Information Service 5285 Port Royal Road Springfield, VA 22161

Available electronically at http://gltrs.grc.nasa.gov 


\title{
Evaluation of an Outer Loop Retrofit Architecture for Intelligent Turbofan Engine Thrust Control
}

\author{
Jonathan S. Litt \\ U.S. Army Research Laboratory \\ Glenn Research Center \\ Cleveland, Ohio 44135 \\ T. Shane Sowers \\ Analex Corporation \\ Brook Park, Ohio 44142
}

\begin{abstract}
The thrust control capability of a retrofit architecture for intelligent turbofan engine control and diagnostics is evaluated. The focus of the study is on the portion of the hierarchical architecture that performs thrust estimation and outer loop thrust control. The inner loop controls fan speed so the outer loop automatically adjusts the engine's fan speed command to maintain thrust at the desired level, based on pilot input, even as the engine deteriorates with use. The thrust estimation accuracy is assessed under nominal and deteriorated conditions at multiple operating points, and the closed loop thrust control performance is studied, all in a complex real-time nonlinear turbofan engine simulation test bed. The estimation capability, thrust response, and robustness to uncertainty in the form of engine degradation are evaluated.
\end{abstract}

\section{Nomenclature}

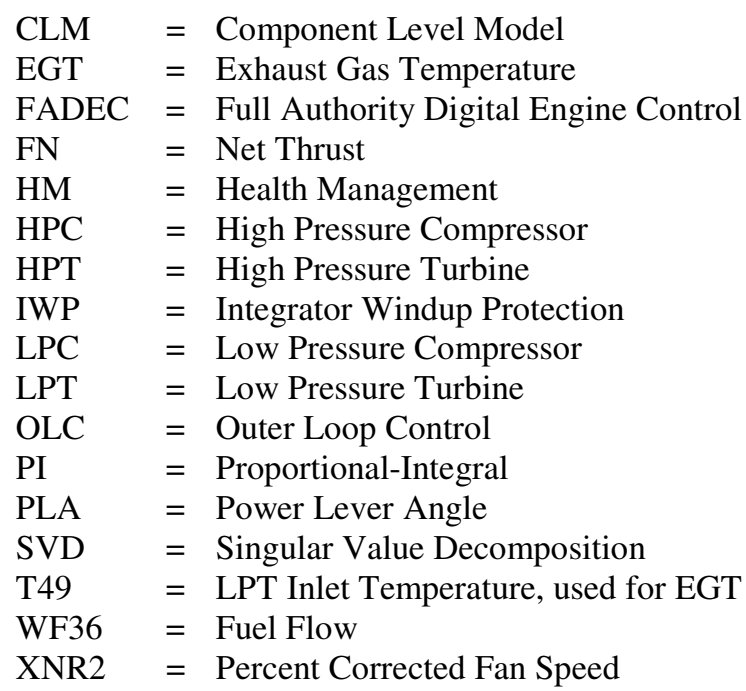

\section{Introduction}

Variations in turbofan engine performance can be attributed to several factors including manufacturing
tolerances and deterioration caused by use. These variations manifest themselves as shifts in engine variables, which with use will eventually drive the engine to the limit of operability. Thus the control system must be robust 
enough to keep the engine operating within acceptable boundaries for several thousand flight cycles. In a typical turbofan control system, the pilot's throttle command is used to set fan speed, which is assumed to be highly correlated to engine thrust, the unmeasured variable of interest. However, as the engine ages, the relationship between fan speed and thrust changes, so in a degraded engine the thrust level is often different from that produced by a new engine for the same throttle setting. In a multi-engine aircraft, this can cause a thrust imbalance and unwanted yawing. If thrust were directly controlled, this situation could be avoided. It is possible to achieve this result using fan speed control by adjusting the fan speed reference signal to accommodate the degraded throttle-tothrust relationship.

The adjustment of fan speed command implies the use of an outer loop control. Knowing how much to adjust it, and more importantly why it needs to be adjusted, implies intelligence. An Intelligent Propulsion Control architecture is one that increases the level of autonomy of the engine. In this context it means that it should at least be able to recognize performance deterioration, diagnose faults, and alter its power setting to recover whatever lost thrust is possible within the physical constraints of the system, even with degraded capability. ${ }^{1}$ Thus an instantiation of such an architecture should be populated with at least some basic diagnostic/health management functions along with some model-based reasoning ability about the engines' degraded performance and operability. A conceptual architecture of this type was developed and the outer loop thrust control was demonstrated to reduce pilot workload in cases where the engines suffered from unequal levels of deterioration, by automatically balancing thrust. ${ }^{2}$ The current paper focuses on the interaction between the outer loop control portion of the architecture and a single engine, in order to evaluate the effectiveness of the approach in the presence of uncertainty of the forms typically encountered: model mismatch, nonlinearities, noise, etc.

The remaining portions of this section give an overview of pertinent aspects of the turbine engine industry's method of engine control as well as an approach that enables the implementation of an Intelligent Propulsion Control architecture, given the current practice. This is followed by a description of the proposed architecture in general, then details of the current implementation, specifically the thrust estimator and outer loop control. Results of an evaluation of the outer loop control to various degradation scenarios are presented next. Finally, conclusions are drawn about the robustness of the implementation.

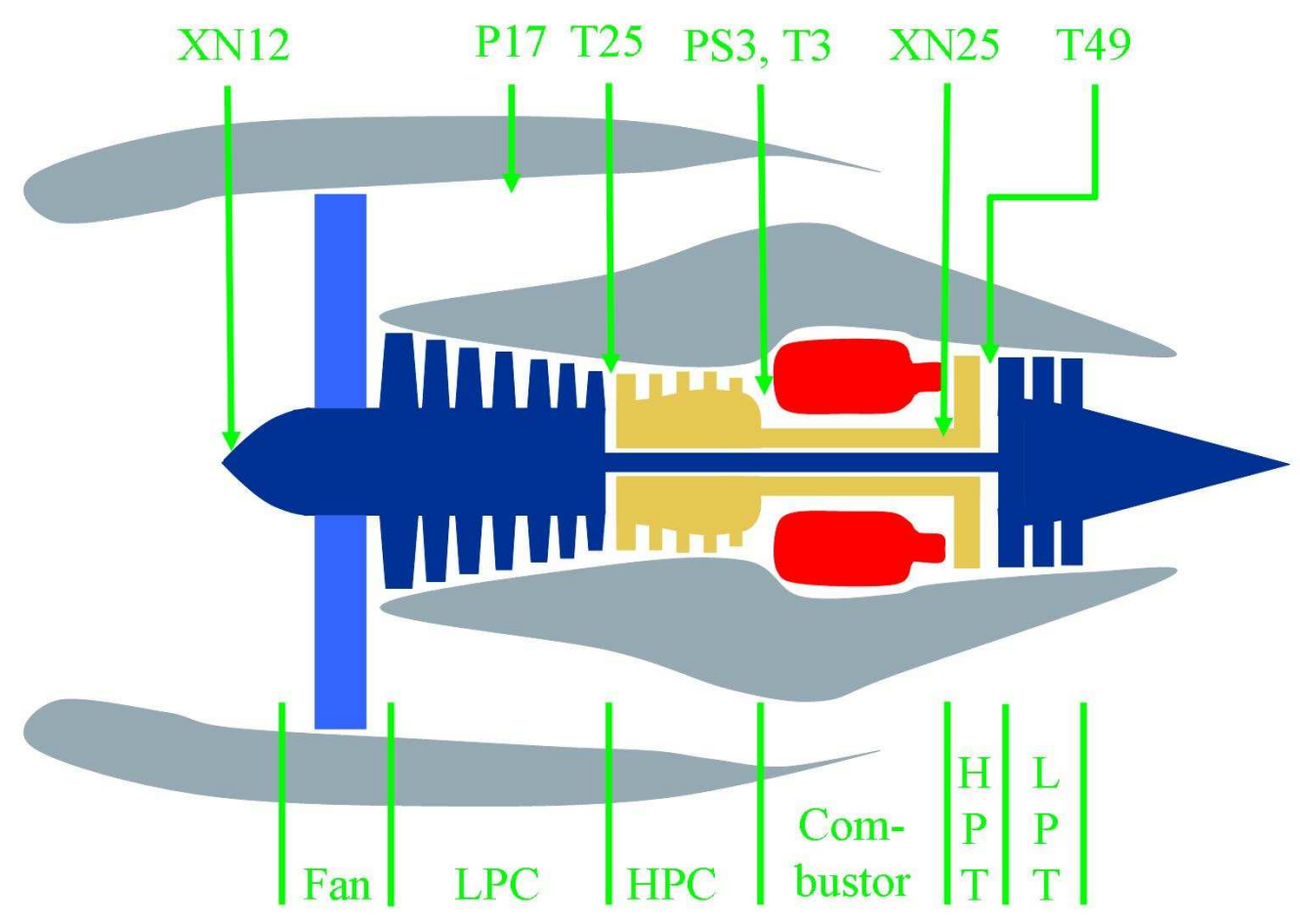

Figure 1. Cross section of a high-bypass commercial-type turbofan engine. 


\section{A. Turbofan Engine Operation and Degradation}

A commercial turbofan engine gas path consists of both rotating and non-rotating components arranged from inlet to exhaust (Figure 1). The first rotating component of a turbofan engine is the fan, which is behind the engine inlet, and in a commercial engine it provides most of the thrust by accelerating a vast quantity of air in the front of the engine and exhausting it directly out the back, bypassing the other components. A small percent of the air passes through the remaining rotating components of the engine. The first of these remaining components is the low pressure compressor (LPC), which is followed by the high pressure compressor (HPC). This opens into the combustor where fuel is injected and burned. The resulting hot gas drives the high pressure turbine (HPT) and the low pressure turbine (LPT), which power the fan and compressors. Each of these components affects the engine's performance, and the performance degradation is embodied in component health. The state of each component's health involves characteristics that degrade over time: such features as efficiency, flow capacity, and seal leakage. These tend to change slowly over many flights, but may change abruptly with the occurrence of a sudden fault. A change of as little as several percent to efficiency and flow capacity may represent the full permissible degradation range of the component.

\section{B. Propulsion Control}

The development of control laws for a turbine engine is an involved process. Typical aircraft engine control systems maintain fan speed or engine pressure ratio to regulate thrust, which is not directly measurable. The controllers are generally based on a variant of a Proportional-Integral (PI) scheme, combined with limit logic (Figure 2). This limit logic consists of a series of min select and max select blocks, each of which selects a fuel flow rate command based on various physical limits, acceleration/deceleration schedules (reference signal for rotor speed rate-of-change vs. rotor speed), and the current operating state (speed governor loops). The final command that exits the selection logic block is integrated to produce a new total fuel flow. ${ }^{3}$ Thus an increment of zero will result in no change in fuel flow, and a constant steady fuel flow will occur when steady state error is eliminated. Other actuators, such as bleed valves and guide vanes, are scheduled open loop, which means that they receive a pre-determined command based on sensed parameters.

The limit logic is quite complex to develop and validate, and extensive simulation testing is required before it is ready to be implemented. The logic might be developed in a block diagram language format that can be compiled into executable code that runs on a flight-certified Full Authority Digital Engine Control (FADEC). The FADEC software implementation must go through a rigorous verification and validation process to meet stringent certification requirements. ${ }^{4}$ The time and cost involved in developing and certifying an engine controller make it prohibitive to perform any modification to existing FADEC code.

\section{Retrofit Architectures}

A retrofit control architecture is one that can be added on top of an existing structure without significant modification. It should alter the signals into or out of the existing controller, but the controller itself should remain intact. For a complex system that requires certification, it might be easier to add externally than to start from scratch, so that, if anything, only the new portion needs additional certification. Reference 2 discusses an architecture of this form that adjusts the command going into the controller of a degraded engine in order to provide the equivalent

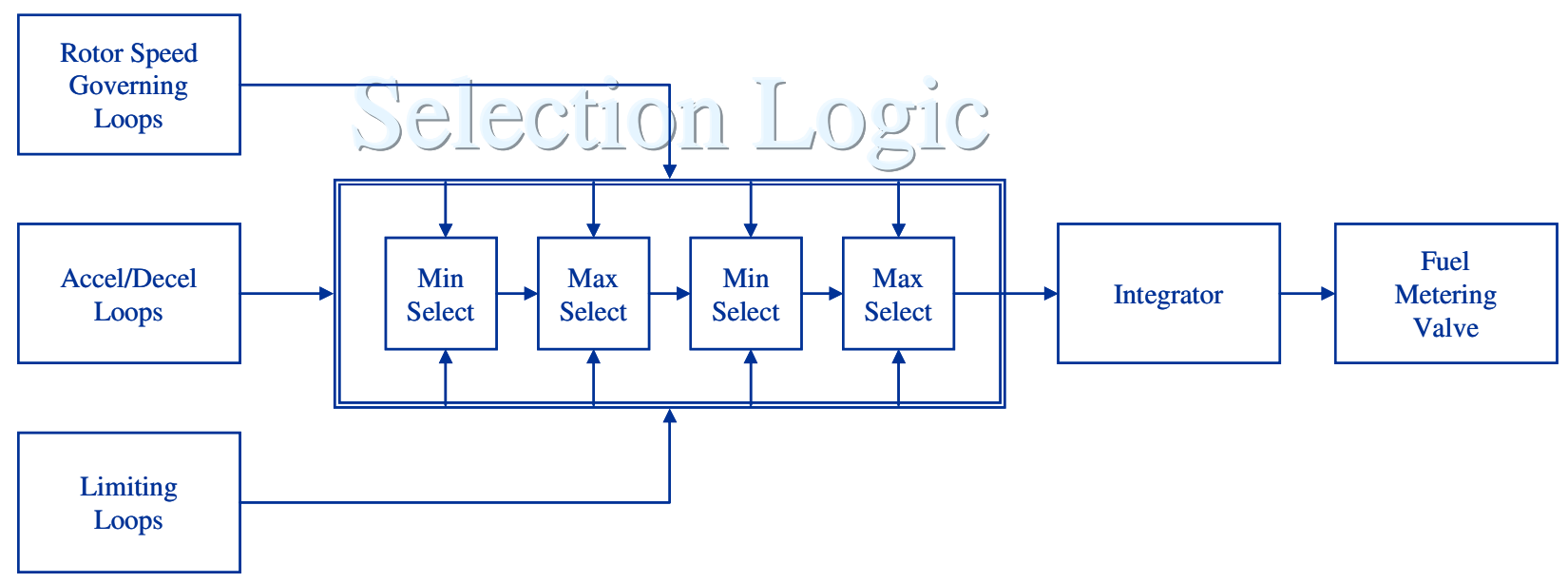

Figure 2. Typical turbine engine control logic. 


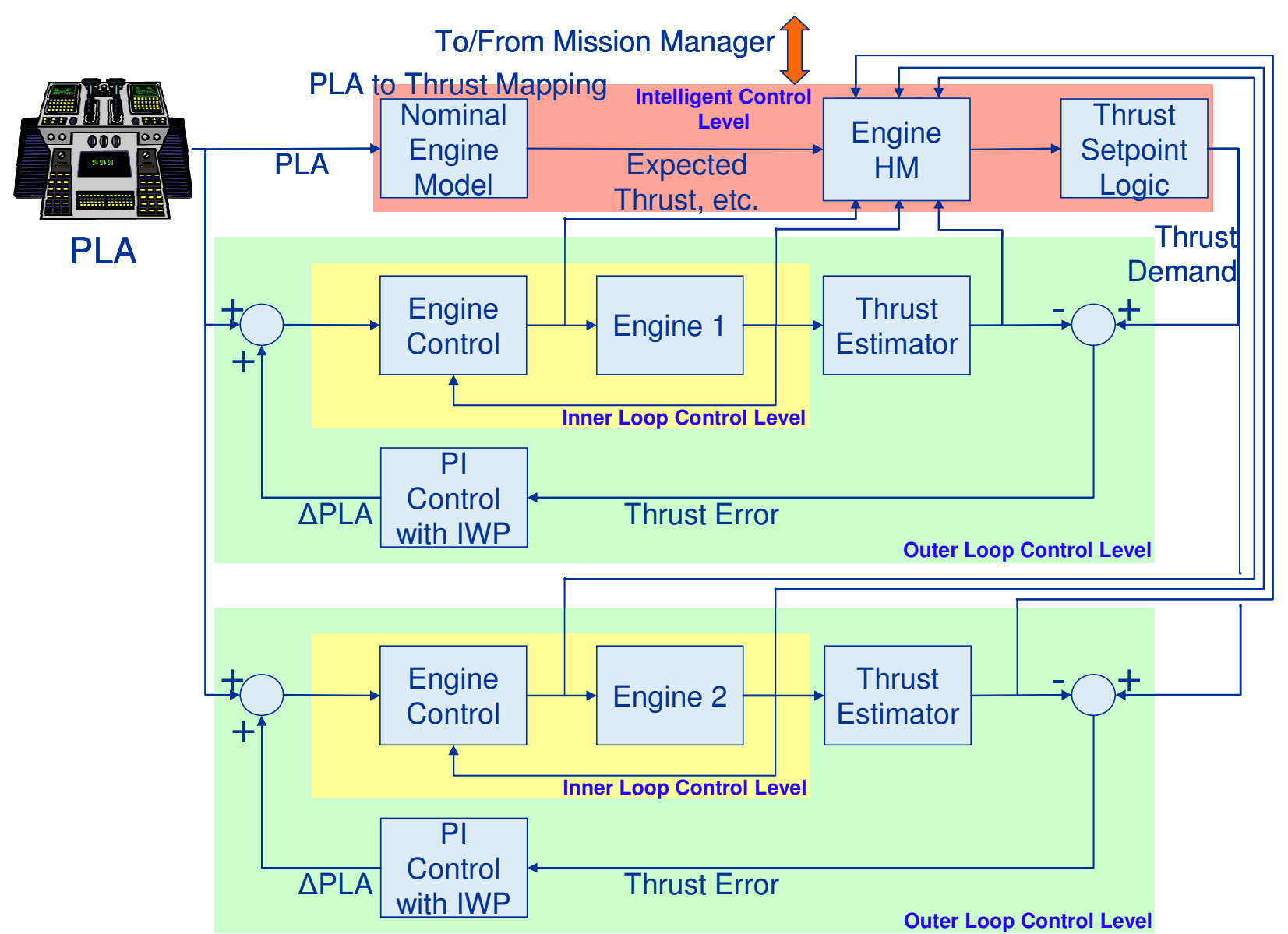

Figure 3. Intelligent retrofit architecture. The hierarchical structure consists of the Inner Loop Control (in the yellow boxes), the Outer Loop Control (in the green boxes), and the Intelligent Control (in the salmon box).

thrust of a new engine. The development of an Intelligent Control structure for the propulsion system of an airplane can reduce pilot workload, improve diagnostic capability and fault-tolerant operation, and can thus benefit safety and operability, but because of the complexity of the FADEC, it is an excellent candidate to be implemented as a retrofit.

\section{Overview of Intelligent Retrofit Architecture}

The proposed retrofit architecture, introduced in Reference 2, is shown in Figure 3. The purpose of the architecture is to automatically maintain balanced thrust as the engines deteriorate with use. The system works by adjusting the fan speed setpoint of each engine individually so that its net thrust is the same as for a new engine for the demanded Power Level Angle (PLA, the pilot's throttle input), within the physical constraints of the system. The architecture is hierarchical with the lowest level performing standard engine control, the next level up maintains balanced thrust with an outer loop thrust control, and the top level consists of the health management and intelligent thrust demand logic. This whole structure is below the flight/mission level. The role of the mission level controller (or intelligent flight controller) is to carry out a mission determined by the capabilities of the overall system (engines and airframe) and modify it based on new information about the situation and the health of the system. For instance, if the engine is unable to meet the demand in a safe way, this information would be reported to the intelligent flight controller or mission manager and the set point is adjusted by logic to maintain balanced thrust at a safe level. The mission manager will not be considered here. Figure 3 shows the overall architecture in block diagram form. The blocks in yellow represent the engines under standard closed loop fan speed control. Above each of the yellow blocks hierarchically is a thrust estimator which generates an estimate of the thrust the engine is producing for use 
with the outer loop thrust control (green boxes). The blocks along the top in the salmon box represent the structure of an intelligent control framework. They consist of the throttle to output (thrust, etc.) mapping, the Health Management (HM) block, and the thrust setpoint logic for the outer loop control. The HM block determines the fitness of the engine to carry out the expected mission, and finds a way to achieve it if possible, through the thrust setpoint logic. Otherwise it coordinates with the Mission Manager to modify the requirements on the engine to an acceptable level.

\section{A. Inner Loop Control}

The Inner Loop Control Level (yellow box in Figure 3) contains the standard engine controller. It is usually a FADEC which is designed to maintain fan speed for performance while not exceeding operability limits. It consists of an incremental PI controller for steady state fan speed control, as well as acceleration and deceleration schedules and other limit logic. The pilot's input to the controller is PLA, which is mapped to a corrected fan speed command; the engine is controlled to this value.

\section{B. Outer Loop Control}

The Outer Loop Control (green box in Figure 3) adjusts the reference signal for the Inner Loop Control. In general, the PLA or throttle, which is a pilot input, sets the fan speed command that is calibrated to achieve a desired thrust. However, with engine degradation or some other change in the throttle-to-thrust relationship, the PLA setting will not produce the desired thrust. In order to bring the thrust to the correct level, the fan speed command is adjusted by the outer loop controller. The FADEC logic is designed to prevent the engine from operating in an unsafe mode, so the incremental PLA value (the adjustment due to the outer loop control, so that the resulting fan speed command results in the desired thrust level), which enters the FADEC along with the pilot input PLA, will not drive the engine into an inappropriate operational regime. The change in fan speed command is obtained by driving the error in thrust to zero. Since thrust is not measurable in flight, it must be estimated. The thrust estimator implemented here uses a Kalman filter with an optimal reduced order model of the effect of engine degradation. ${ }^{5}$ The inputs to the Kalman filter are corrected fuel flow, the open loop scheduled actuators (Variable Bleed Valve and Variable Stator Vanes) and the seven corrected sensed engine variables. The use of corrected variables as inputs to the linear estimator extends its range because the correction factors have the effect of transforming the engine operating condition to a standard operating point, ${ }^{6}$ usually sea level, standard day. This allows meaningful comparison of engine data at different conditions and different levels of degradation. ${ }^{7}$ In a practical sense, it enables the Kalman filter to accurately estimate the thrust of a degraded engine at an operating point far from the point where the optimal linear estimator was designed. The difference between the estimated and desired thrust is fed through a PI controller which adjusts the fan speed command by manipulating PLA until the thrust error is zero. The Outer Loop Control level contains integrator windup protection (IWP) on the PI controller. The outer loop controller is tuned to avoid introducing unwanted dynamics. It is important that the inner and outer loop controllers are operating on different time scales to avoid interaction; since the inner loop provides direct control while the outer loop adjusts the reference signal, the outer loop should respond more slowly.

\section{Intelligent Control}

The Intelligent Control Level (salmon box in Figure 3) contains the parts of the control structure that evaluate the safety, performance, and capabilities of the engines. Unlike the lower levels for which each engine had a copy, there is only a single copy of this level; it monitors the propulsion system of the aircraft. It takes input from both engines (control signals, sensed variables, thrust estimate, etc.) to determine each engine's current health and fitness for the mission. It also generates the outer loop thrust command that both engines follow. Ideally, activity at the Intelligent Control Level will be limited to assessment and consent, but as the engines age and degrade, or when an anomaly occurs, the health management algorithms determine the appropriate action, which generally has to do with the fan speed setting. If the Intelligent Control determines that the condition of an engine is such that corrective action is beyond the scope of the propulsion control (for instance, a problem that might compromise the mission) it communicates this information to the Mission Manager. What the Intelligent Control does not do is adapt the inner loop control; since this is a retrofit architecture it is specifically designed to adjust the signal going into the FADEC, not the FADEC itself.

\section{Test Setup}

The focus of this paper is the thorough evaluation of the thrust control portion of the architecture implemented with a single engine across a wide operating range. Thus the emphasis is on thrust estimation capability and closed 
Table 1. State Variables, Health Parameters, Actuators, and Auxiliary Output

\begin{tabular}{cccc}
\hline State Variables & Health Parameters & Actuators & Auxiliary Output \\
\hline Fan Speed, XN12 & FAN efficiency & Fuel Flow, WF36 & Thrust, FN \\
Core Speed, XN25 & FAN flow capacity & Variable Bleed Valve, VBV & \\
metal temperature 1 & LPC efficiency & Variable Stator Vanes, VSV & \\
metal temperature 2 & LPC flow capacity & & \\
metal temperature 3 & HPC efficiency & \\
metal temperature 4 & HPC flow capacity & \\
metal temperature 5 & HPT efficiency & \\
metal temperature 6 & HPT flow capacity & \\
metal temperature 7 & LPT efficiency & \\
\hline & LPT flow capacity & \\
\hline
\end{tabular}

Table 2. Sensor Sets and Sensor Standard Deviation (Std. Dev. as \% of Steady-State Values at Full Power)

\begin{tabular}{cc}
\hline Sensor Set (Figure 1) & Standard Deviation (\%) \\
\hline XN12 (rotational speed) & 0.25 \\
\hline XN25 (rotational speed) & 0.25 \\
\hline P17 (pressure) & 0.50 \\
\hline T25 (temperature) & 0.75 \\
\hline PS3 (pressure) & 0.50 \\
\hline T3 (temperature) & 0.75 \\
\hline T49 (temperature) & 0.75 \\
\hline
\end{tabular}

loop command tracking. The airframe and related issues such as thrust asymmetry with multiple engines, and pilot workload reduction have already been reported. ${ }^{2}$ Functions of the Intelligent Control level beyond the nominal engine model and corresponding thrust setpoint logic will not be evaluated, i.e., diagnostic algorithms per se will not be evaluated.

\section{A. Real-time hardware-in-the-loop implementation and testing}

The closed loop system was set up on two asynchronous computers, one executing the simulation of the large commercial turbofan engine in real time, the other executing the outer loop thrust control portion of the hierarchical controller including the FADEC-like engine control.

\section{B. Large Commercial Turbofan Engine Simulation}

The engine is represented by a nonlinear Component Level Model (CLM) simulation. The model has nine state variables, 10 health parameters, three control inputs, and one auxiliary (unmeasured) output all shown in Table 1, as well as seven sensors shown in Table 2 (see Figure 1 for sensor locations). It must be noted that for this work, the more common P25 measurement is replaced by P17; without this substitution, thrust estimation is poor. ${ }^{5}$ This indicates that the ability to estimate unmeasured outputs is strongly influenced by sensor selection. The Exhaust Gas Temperature (EGT) is represented by T49.

\section{Piecewise linear model}

A piecewise linear model is composed of a set of linear models derived at multiple operating conditions. Through interpolation of the linear models, the piecewise linear model is able to represent the original nonlinear system over a wide operating range. ${ }^{8}$ A piecewise linear model is used as the basis for both the nominal model which provides the outer loop thrust reference command, and the Kalman filter that performs the thrust estimation. The piecewise linear model is developed by linearizing the CLM at multiple altitude-Mach number-PLA triples, with PLA varying across its range for each altitude-Mach number pair shown in Figure 4; these altitude-Mach number pairs are selected to be along a typical takeoff/climb/cruise trajectory of a commercial turbofan engine. Each linear model consists of the linear dynamics in state space form and trim values for all variables. In the piecewise linear model structure, the trim values and the state space matrices are linearly interpolated using percent corrected fan speed and environmental condition (a function of ambient pressure and engine inlet pressure, which are related to altitude and Mach number) as the scheduling parameters. While all trim points are used, it was found that interpolating the dynamics from just the sea level static and cruise points (altitude-Mach number-PLA triples) provide sufficient fidelity to match the CLM in the neighborhood of the linearization points in most cases, and 


\section{Flight Envelope}

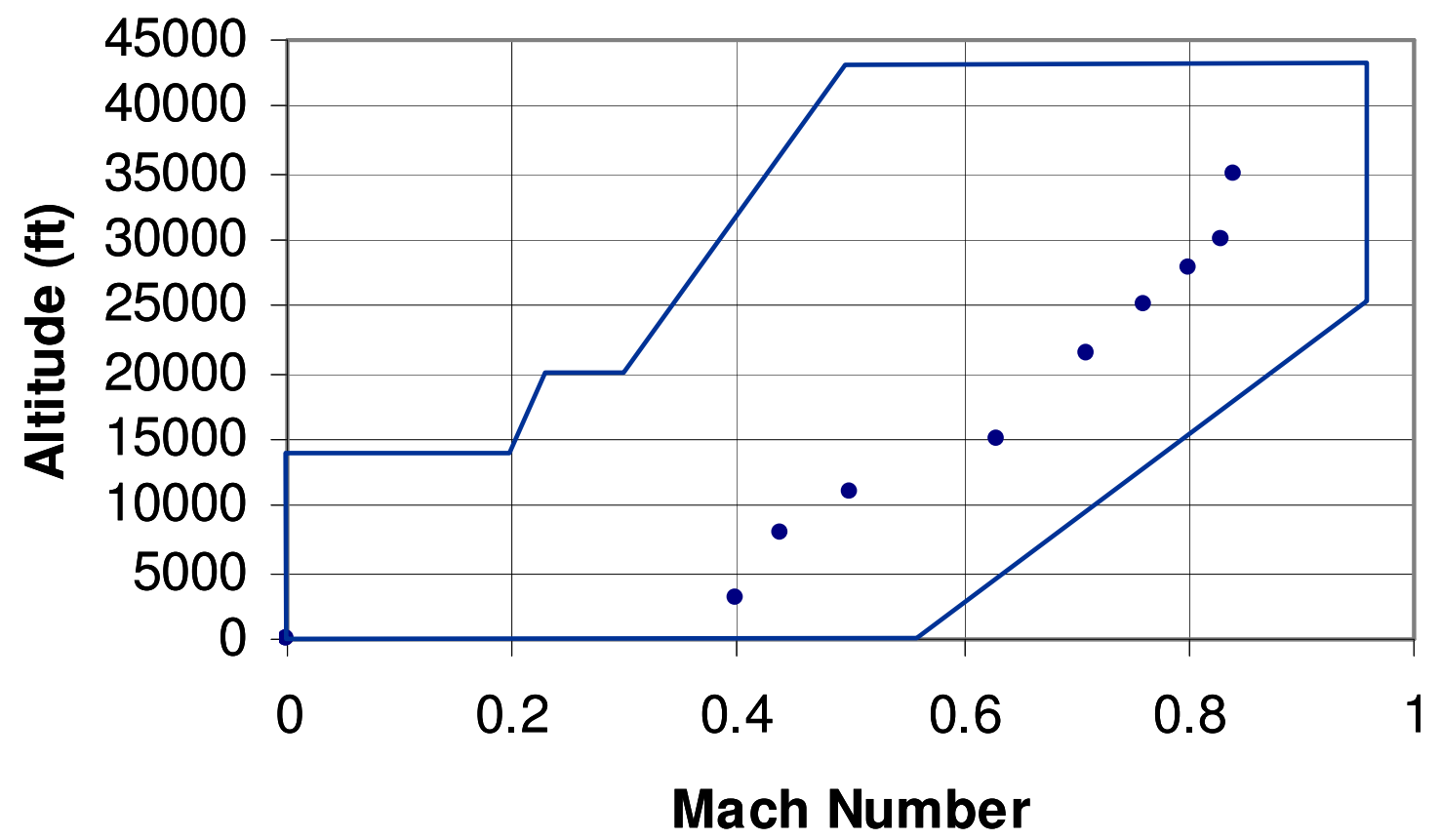

Figure 4. Flight envelope of the engine showing points along the takeoff/climb/cruise trajectory.

adding more sets does not significantly improve the results. The piecewise linear model that represents the nominal engine does not account for degradation, either in the trim values or the dynamics. In the final implementation of the nominal model which provides the thrust reference, just the interpolated trim points were used; the dynamics are unnecessary due to the outer loop's relatively slow time scale.

\section{Thrust Estimation}

The Kalman filter used for thrust estimation is based on the piecewise linear model but it does account for degradation through the incorporation of additional sensitivity matrices relating the health parameters to the other variables. The special procedure to modify the linear models used to obtain the Kalman gains is described below. The Kalman filter equations are interpolated the same way as those of the piecewise linear model.

The problem of thrust estimation using a Kalman filter has been addressed ${ }^{5}$ and demonstrated in a flight simulator in the neighborhood of a single operating point. ${ }^{2}$ The difficulty in implementing a direct thrust control system arises because thrust is not directly measurable and the relationship between fan speed and thrust changes with engine deterioration. If engine deterioration could be estimated, thrust could be reconstructed fairly accurately, but the limited number of sensors on a typical commercial engine makes the deterioration estimation problem underdetermined. The optimal linear approach of Ref. 5 utilizes singular value decomposition (SVD) to reduce the number of parameters to be estimated. This can be seen by examining the linearized engine model, which has the form

$$
\begin{aligned}
& \dot{x}=A x+B u+L p+w \\
& y=C x+D u+M p+v \\
& z=E x+F u+N p
\end{aligned}
$$

where the health parameter vector, $p$, appears as input to the system, the auxiliary parameter vector $z$ represents thrust, $L, M$, and $N$ are sensitivity matrices of the appropriate dimension, $w$ and $v$ represent noise. For estimation, eq. (1) can be rearranged as 


$$
\begin{aligned}
{\left[\begin{array}{c}
\dot{x} \\
\dot{p}
\end{array}\right] } & =\left[\begin{array}{cc}
A & L \\
0 & 0
\end{array}\right]\left[\begin{array}{l}
x \\
p
\end{array}\right]+\left[\begin{array}{l}
B \\
0
\end{array}\right] u+w \\
y & =\left[\begin{array}{ll}
C & M
\end{array}\right]\left[\begin{array}{l}
x \\
p
\end{array}\right]+D u+v \\
z & =\left[\begin{array}{ll}
E & N
\end{array}\right]\left[\begin{array}{l}
x \\
p
\end{array}\right]+F u
\end{aligned}
$$

where the health parameters, which are assumed to vary slowly, appear as state variables and are thus able to be estimated by a Kalman filter as long as the system is observable; unfortunately, typically engines have too few sensors to allow all heath parameters to be estimated. Reference 5 demonstrated that by using SVD to reduce the number of parameters to be estimated, unmeasurable parameters such as thrust may be estimated in an optimal fashion. This is achieved by approximating $L, M$, and $N$ from eq. (1) by the reduced rank matrix product $\left[L^{T} M^{T}\right.$ $\left.N^{T}\right]^{T} \approx U^{*} V^{*}$, and an observable vector $q \approx V^{*} p$. Thus the approximations to $L, M$, and $N$ all have a common right factor, making them amenable to the reconstruction of unmeasurable outputs. Thus

$$
\left[\begin{array}{c}
L \\
M \\
N
\end{array}\right]=U \Sigma V^{T} \approx\left(U_{k} \Sigma_{k}\right) V_{k}^{T}=U^{*} V^{*}=\left[\begin{array}{c}
U_{L}^{*} \\
U_{M}^{*} \\
U_{N}^{*}
\end{array}\right] V^{*}
$$

where $U^{*}=U_{k} \Sigma_{k}$ and $V^{*}=V_{k}^{T}$ correspond to the $k$ largest singular values of $\left[L^{T} M^{T} N^{T}\right]^{T}$. Thus eq. (2) can be approximated as

$$
\begin{aligned}
{\left[\begin{array}{c}
\dot{x} \\
\dot{q}
\end{array}\right] } & =\left[\begin{array}{cc}
A & U_{L}^{*} \\
0 & 0
\end{array}\right]\left[\begin{array}{l}
x \\
q
\end{array}\right]+\left[\begin{array}{c}
B \\
0
\end{array}\right] u+w \\
y & =\left[\begin{array}{ll}
C & U_{M}^{*}
\end{array}\right]\left[\begin{array}{l}
x \\
q
\end{array}\right]+D u+v \\
z & =\left[\begin{array}{ll}
E & U_{N}^{*}
\end{array}\right]\left[\begin{array}{l}
x \\
q
\end{array}\right]+F u
\end{aligned}
$$

where $q$ replaces $p$ as the vector of tuners that is of low enough dimension to be estimated.

This method can be extended to piecewise linear models by stacking the sensitivity matrices that relate the degradation to shifts in the state, sensed, and auxiliary variables from all linearization points to obtain a single right factor and thus a common $q$ vector across the flight envelope as

$$
\left[\begin{array}{c}
L_{1} \\
M_{1} \\
N_{1} \\
\vdots \\
L_{n} \\
M_{n} \\
N_{n}
\end{array}\right]=\left[\begin{array}{c}
U_{L_{1}} \\
U_{M_{1}} \\
U_{N_{1}} \\
\vdots \\
U_{L_{n}} \\
U_{M_{n}} \\
U_{N_{n}}
\end{array}\right] \Sigma V^{T} \approx\left[\begin{array}{c}
U_{L_{1}}^{*} \\
U_{M_{1}}^{*} \\
U_{N_{1}}^{*} \\
\vdots \\
U_{L_{n}}^{*} \\
U_{M_{n}}^{*} \\
U_{N_{n}}^{*}
\end{array}\right] V^{*}
$$

The SVD approach to model order reduction defines the optimal set of tuners in a least squares sense. In this case, 10 health parameters are replaced by seven tuners, thus introducing additional, albeit known modeling error. ${ }^{5}$ The optimality of the approach lies in the fact that the least information possible is lost during the order reduction, and the SVD methodology achieves this by retaining the seven largest of the 10 singular values. Table 3 lists the singular values from this implementation, and it can be seen that while the dropped singular values are not insignificant, they are still relatively small compared to those that are retained. 
Table 3. Singular Values of the Health Parameter Sensitivity Matrices (shaded singular values are dropped)

\begin{tabular}{|c|c|c|c|c|c|c|c|c|c|}
\hline$\sigma_{1}$ & $\sigma_{2}$ & $\sigma_{3}$ & $\sigma_{4}$ & $\sigma_{5}$ & $\sigma_{6}$ & $\sigma_{7}$ & $\sigma_{8}$ & $\sigma_{9}$ & $\sigma_{10}$ \\
\hline 28.111 & 20.299 & 15.936 & 12.071 & 9.9994 & 7.2892 & 5.0358 & 3.782 & 2.1 & 1.6902 \\
\hline
\end{tabular}

\section{E. Proportional-Integral Control with Integrator Windup Protection}

A PI controller is used in the outer loop to adjust the PLA value entering the FADEC such that desired thrust is achieved. The PI controller implemented here has fixed gains and is tuned to give an acceptable response for the takeoff/climb/cruise trajectory used for testing. In an implementation designed to cover more of the flight envelope, a gain-scheduled PI controller might need to be designed. Integrator Windup Protection is necessary for the outer control loop because it delivers a $\triangle \mathrm{PLA}$ command to the inner loop control, which could potentially result in a gross value above the maximum PLA limit, especially in cases where a degraded engine's thrust is significantly lower than nominal for a given PLA. Since this would result in a saturating command, the integral term would tend to wind up, resulting in an oscillatory response. The protection scheme implemented here is the simple conditional integration or integrator clamping where the integration is stopped and the value fixed once the limit is reached, and integration is only restarted when the appropriate condition (total PLA entering the FADEC $\leq$ maximum) is fulfilled. ${ }^{9}$

\section{Evaluation Results}

The engine is represented by a full envelope, nonlinear, high fidelity simulation, and the controller consists of the Inner Loop and Outer Loop levels as well as the Nominal Engine Model from the hierarchical intelligent control architecture shown in Figure 3, with the inner-loop engine control maintaining fan speed. Many scenarios are run to evaluate the system's performance in real time, using a wide range of component degradation values. The scenarios are limited to cases where fan speed adjustment is all that is required.

\section{A. Evaluation approach}

The evaluation approach utilizes a nonlinear simulation with 10 adjustable health parameters, and a piecewise linear Kalman filter to estimate thrust up to the degradation limit of the engine. The evaluation is performed in two stages. First, steady state testing is performed, initially of the thrust estimate, and then of outer loop thrust control at multiple operating points and degradation conditions. If the thrust estimator is able to reconstruct the true thrust accurately, then it stands to reason that the thrust can be controlled to match that of the nominal engine as long as it is within the physical limits of the engine to do so. Second, transient testing is performed under outer loop control, where engines of various health conditions are run through a takeoff/climb/cruise trajectory to confirm that nominal thrust response can be attained by a degraded engine.

\section{B. Steady State Evaluation}

The purpose of the steady state evaluation is to determine the accuracy of the thrust estimation and control at several linearization points. Variations in the level of degradation of the nonlinear engine simulation are used with and without sensor noise to test the performance of the closed loop system. Results are reported for thrust estimation at multiple levels of engine degradation and PLA values, and for outer loop thrust control at values of PLA away from the maximum PLA saturation limit.

First the simplest scenario is checked. The thrust estimation accuracy is evaluated at each of the 10 steady state operating points (Figure 4) for multiple PLA values. The normalized results of evaluating 50 random levels of deterioration ranging from 1-5\% in each health parameter without sensor noise appear in Table 4. Normalization is performed by dividing the data gathered at each operating point by the nominal thrust level at that operating point. It can be seen that the error is generally small, indicating good accuracy over the operating range. The estimation error and its standard deviation tend to be larger at the operating points in the middle and smaller at the ends, which is to be expected because, as previously mentioned, only the state space matrices from the two end points are interpolated in the piecewise linear model. An unexpected result, which can be seen by comparing the magnitudes of the mean of the error and the mean of the absolute error, is that they are the same in most cases, indicating that there is a directional bias in the estimation error; this is probably due to the modeling error introduced by the reduced order approximation using SVD. 
Table 4. Percent Normalized Mean Error, Standard Deviation, and Mean Absolute Error of thrust estimation at multiple operating points (Figure 4), no noise, 50 random levels of deterioration ranging from $1-5 \%$ in each health parameter.

\begin{tabular}{|c|c|c|c|c|c|c|c|c|c|c|c|}
\hline $\begin{array}{c}\text { PLA } \\
\downarrow\end{array}$ & $\begin{array}{c}\text { Operating } \\
\text { Point }\end{array}$ & 1 & 2 & 3 & 4 & 5 & 6 & 7 & 8 & 9 & 10 \\
\hline \multirow{3}{*}{84} & Mean(\%error) & -0.01 & 1.53 & 1.55 & 1.66 & 1.28 & 0.94 & 0.55 & 0.11 & -0.20 & -0.30 \\
\cline { 2 - 13 } & StdDev(\%error) & 0.06 & 0.33 & 0.43 & 0.51 & 0.49 & 0.35 & 0.24 & 0.16 & 0.12 & 0.09 \\
\cline { 2 - 12 } & Mean(abs(\%error)) & 0.05 & 1.53 & 1.55 & 1.66 & 1.28 & 0.94 & 0.56 & 0.17 & 0.20 & 0.30 \\
\hline \multirow{4}{*}{70} & Mean(\%error) & 0.13 & 0.74 & 0.67 & 0.90 & 0.95 & 0.67 & 0.37 & -0.03 & -0.25 & -0.31 \\
\cline { 2 - 12 } & StdDev(\%error) & 0.05 & 0.25 & 0.28 & 0.30 & 0.28 & 0.18 & 0.16 & 0.12 & 0.11 & 0.10 \\
\cline { 2 - 12 } & Mean(abs(\%error)) & 0.13 & 0.74 & 0.67 & 0.90 & 0.95 & 0.67 & 0.37 & 0.09 & 0.25 & 0.31 \\
\hline \multirow{3}{*}{60} & Mean(\%error) & -0.05 & 0.63 & 0.51 & 0.56 & 0.52 & 0.53 & 0.09 & -0.23 & -0.44 & -0.44 \\
\cline { 2 - 11 } & StdDev(\%error) & 0.04 & 0.20 & 0.20 & 0.21 & 0.21 & 0.21 & 0.14 & 0.09 & 0.08 & 0.11 \\
\cline { 2 - 12 } & Mean(abs(\%error)) & 0.05 & 0.63 & 0.51 & 0.56 & 0.52 & 0.53 & 0.13 & 0.23 & 0.44 & 0.44 \\
\hline
\end{tabular}
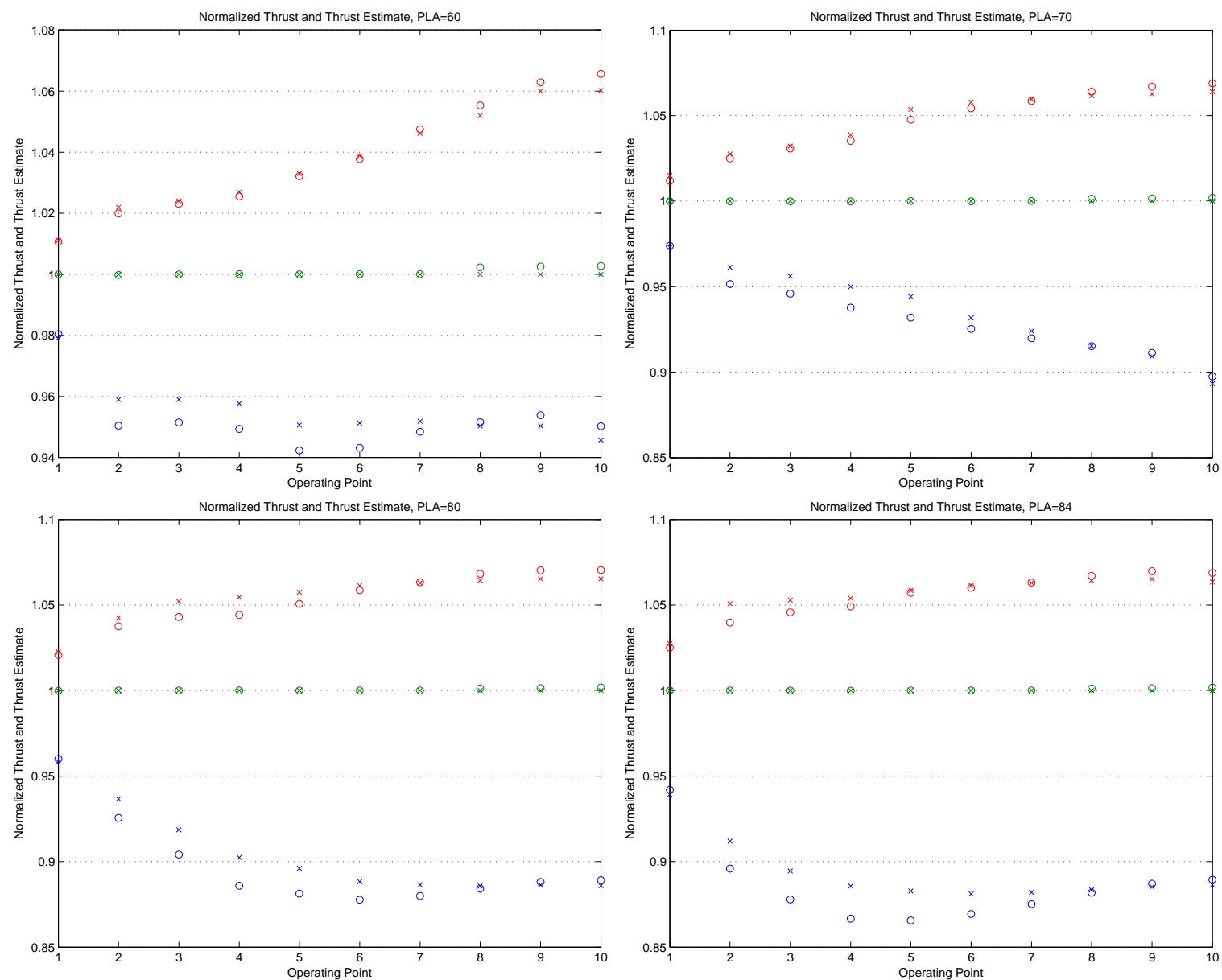

Figure 5. True thrust $(x)$ and thrust estimate $(O)$ for nominal engine and worst case degradation scenarios, nominal in green, cold section (fan, LPC, HPC) degradation in blue, hot section (HPT, LPT) degradation in red, at four constant PLA levels, no sensor noise.

Figure 5 shows the normalized thrust and thrust estimate for the nominal engine as well as for the worst case degradation scenarios at the steady state flight conditions (Figure 4) with various PLA settings, the sensor outputs are not corrupted by noise. In this context, worst case is defined as the largest degradation-induced shift in either direction-5\% reduction in efficiency and flow capacity of each component in the cold section of engine (fan, LPC, HPC) in one case, and 5\% shift in efficiency (reduction) and flow capacity (increase) of each component in the hot 


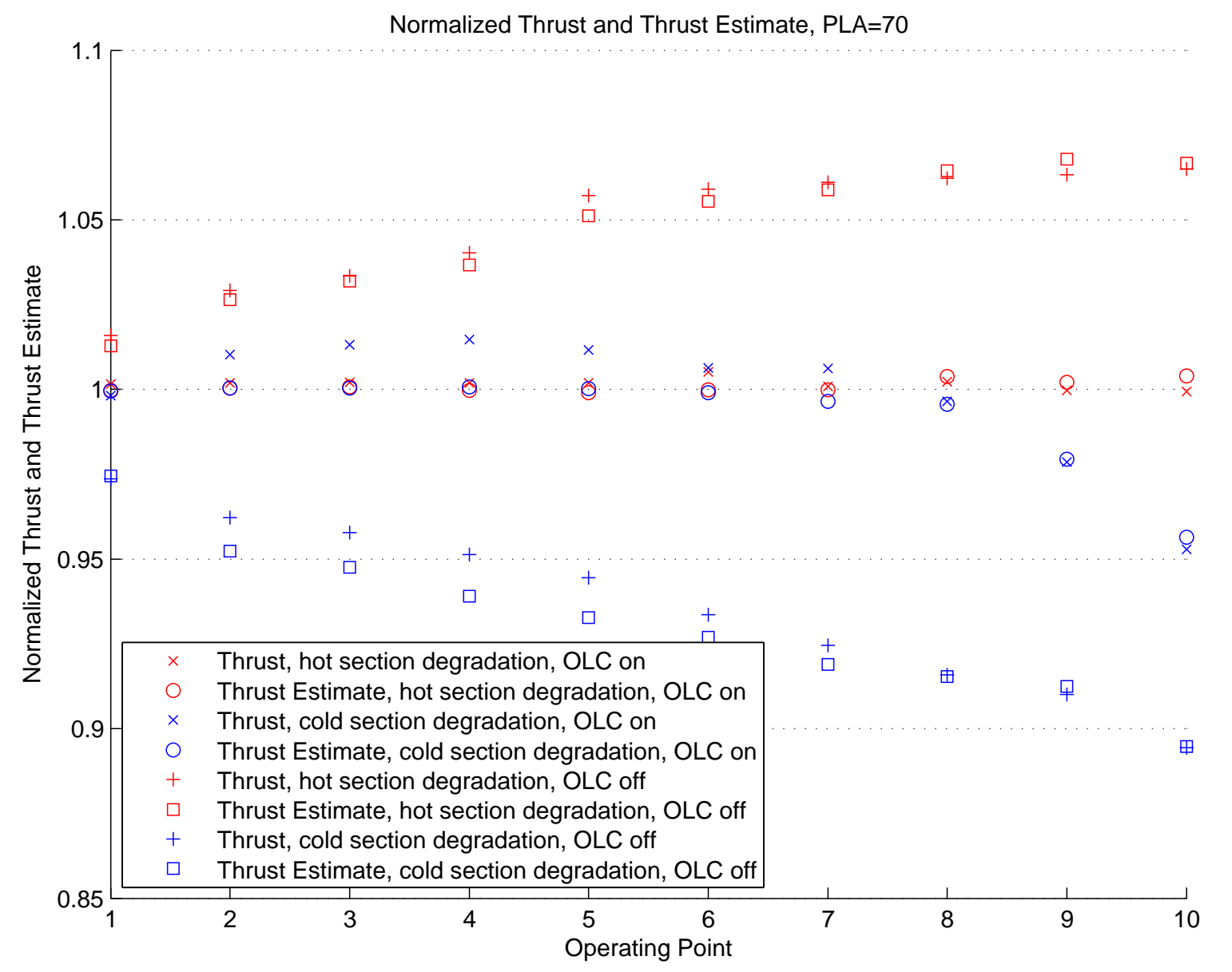

Figure 6. Steady state thrust for worst case degradation at each operating point (Figure 4), with and without outer loop control, PLA=70, sensor noise included, results based on averaging 1000 samples per operating point.

section of engine (HPT, LPT) in the other. ${ }^{2}$ Again, normalization is performed by dividing the data gathered at each operating point by the nominal thrust level at that operating point. Figure 5 demonstrates the relative size of the estimation error to the magnitude of the degradation-induced shift. The error for the cold section degradation case tends to be larger than for the hot section degradation case, which is probably a result of the SVD-based model reduction; this can be fine-tuned if desired. ${ }^{5}$ Since the estimation error is generally small relative to the degradationinduced shift, it suggests that the thrust estimate might be used effectively for outer loop thrust control.

Finally, the steady state scenario is repeated with sensor noise added and outer loop thrust control active. A constant PLA value of 70 is used, not near enough to the PLA limit to cause saturation at most test points. Figure 6 shows how thrust is maintained at the correct value at each operating point with worst case hot section degradation. It is clear that for the cold section degradation case, the $\triangle \mathrm{PLA}$ increment saturates the PLA input at the higher operating points and thrust matching is not possible. Even with outer loop control active, the thrust level approaches the value obtained with no outer loop control.

\section{Transient Evaluation}

The transient evaluation involves comparing simulated engine responses with varying levels of degradation with and without outer loop thrust control. The objective is to determine whether the outer loop control is able to maintain the nominal thrust response over a typical flight trajectory. The transient used is a realistic takeoff/climb/cruise trajectory as shown in Figure 7. The trajectory passes though or near each of the 10 linearization points shown in Figure 4, as can be seen in Figure 8, which shows the actual path superimposed on the surface of linearization points. 

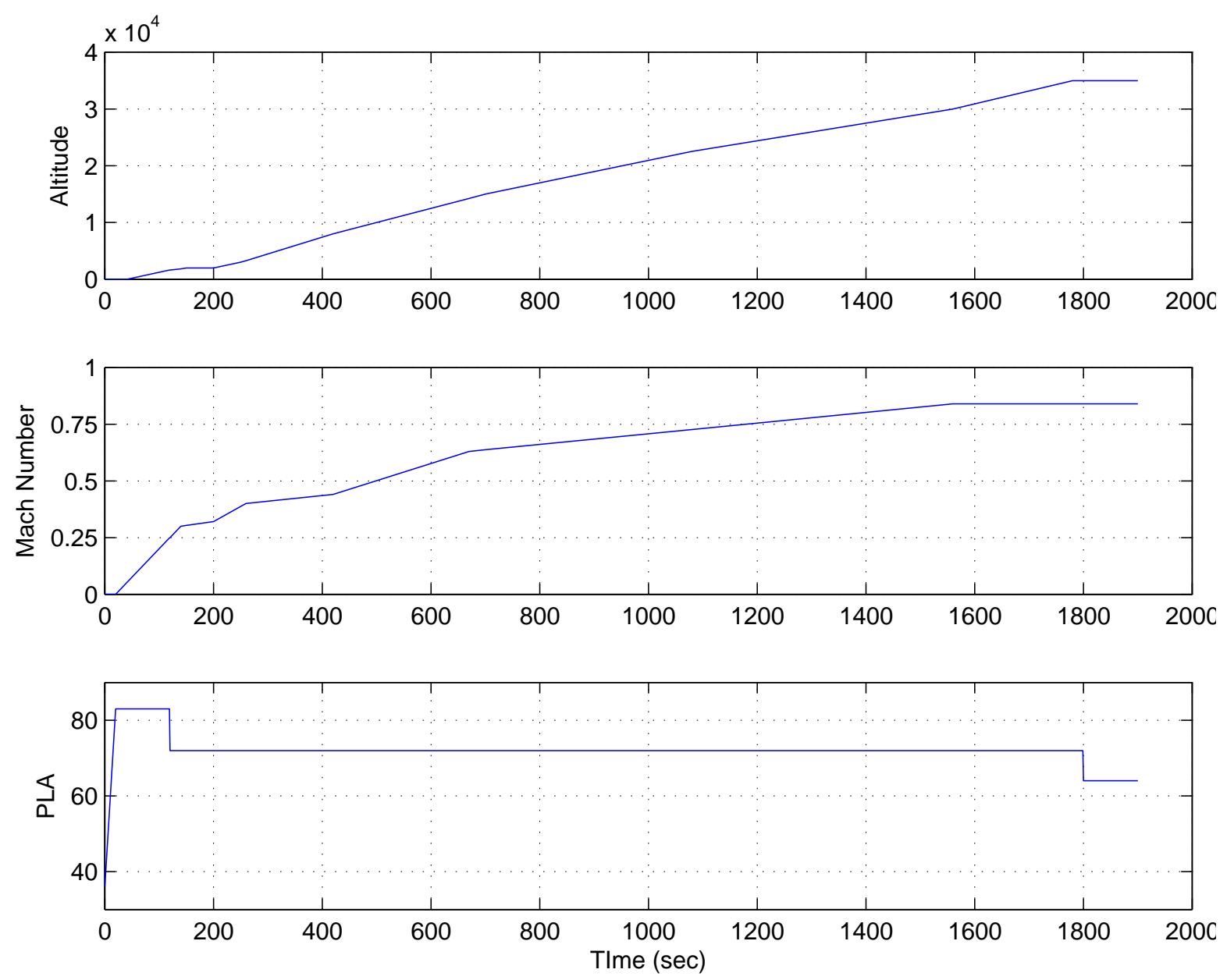

Figure 7. Take-off/climb/cruise trajectory.

Figure 9 though Figure 18 show the worst case scenarios again. Figure 9 through Figure 13 show the cold section of the engine scenario (fan, LPC, HPC) where deterioration reduces thrust. This results in a saturating PLA command (Figure 10) and thrust is only able to track the nominal thrust for part of the transient before they diverge and it moves toward the degraded trajectory. Fuel flow (Figure 11), percent corrected fan speed (Figure 12) and EGT (Figure 13) show increased levels as compared to the nominal and degraded cases, which could be construed negatively. However if a pilot increases the throttle manually to balance thrust the result is the same, and although engine life is closely tied to the temperature and rotational speed, the increased EGT is not a significant concern for creep damage until the overtemperature limit is reached. ${ }^{10}$ Thrust setpoint logic (not included in this implementation) could address these issues by lowering thrust demand, if necessary. An interesting phenomenon is the oscillatory segment in these three variables for the case with no outer loop control. This may be a controller problem, or possibly a numerical issue with the nonlinear simulation rather than a realistic response, but in any case it was not investigated further except to determine that it is fairly repeatable and it is alleviated through use of the outer loop control. Figure 14 through Figure 18 show the degraded hot section case where the opposite effect occurs, thrust increases allowing fuel flow and EGT to be reduced. Thus there is the double benefit of fuel savings as compared to the degraded engine under baseline fan speed control, and lower temperature which translates to potentially slower part life consumption. Since degradation often results in increased thrust, ${ }^{11}$ outer loop thrust control might generally produce these beneficial results. Both Figure 9 and Figure 14 show a large discrepancy between the true and estimated thrust responses near the beginning of the transient. The estimated thrust tracks the thrust reference (the output of the piecewise linear Nominal Engine Model in Figure 3 upon which the thrust estimator is based) rather than the true thrust output of the engine. This is probably due to the fact that the linear models were generated at steady state points, and this portion of the transient covers a large region so quickly that it moves out of the linear range. The fact that the thrust estimator tracks the nominal thrust model indicates that the 


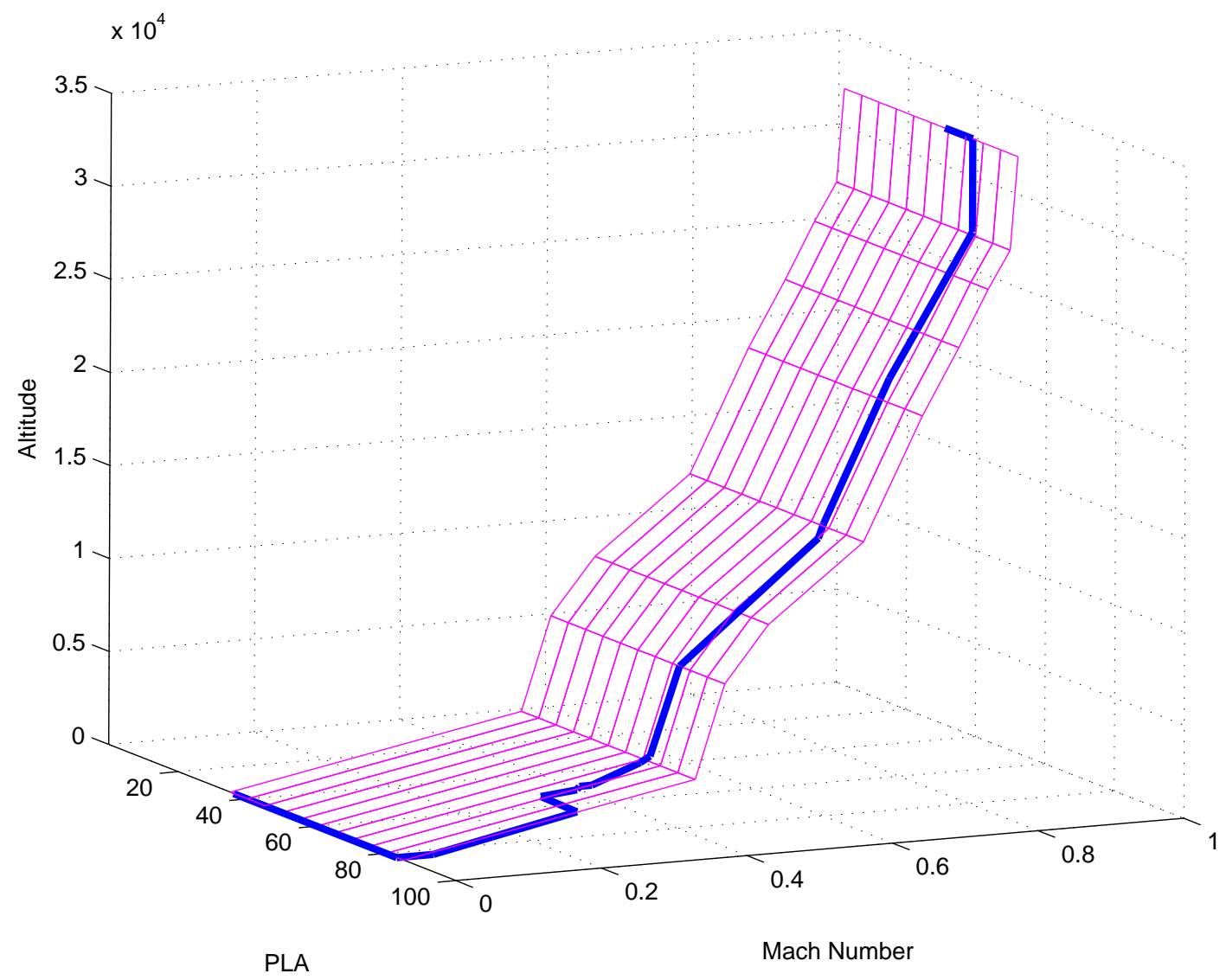

Figure 8. Take-off/climb/cruise trajectory superimposed on surface of linearization points.

error is caused by a modeling issue with the piecewise linear model, and that it is a consistent interpretation of the true thrust based on measured values. Thus, even with this large initial deviation, as long as the outer loop control does not cause PLA to saturate, the thrust racks the nominal thrust, so in a full implementation of the Intelligent Retrofit Architecture, as long as all engines are receiving the same outer loop command, thrust balance will be maintained.

Figure 19 shows a set of five cases of random deterioration with noise. There is a wide spread of thrust values when the baseline fan speed control is used. With outer loop thrust control, the thrust values are all clustered along the thrust command. This can be seen easily in the detail in Figure 20, which also gives some insight into how the outer loop control works. A plot representing one degraded engine under outer loop control saturates PLA and begins to diverge at about 1300 seconds. However, once PLA is reduced to the cruise setting, the saturated variable immediately reconverges to the thrust reference. 


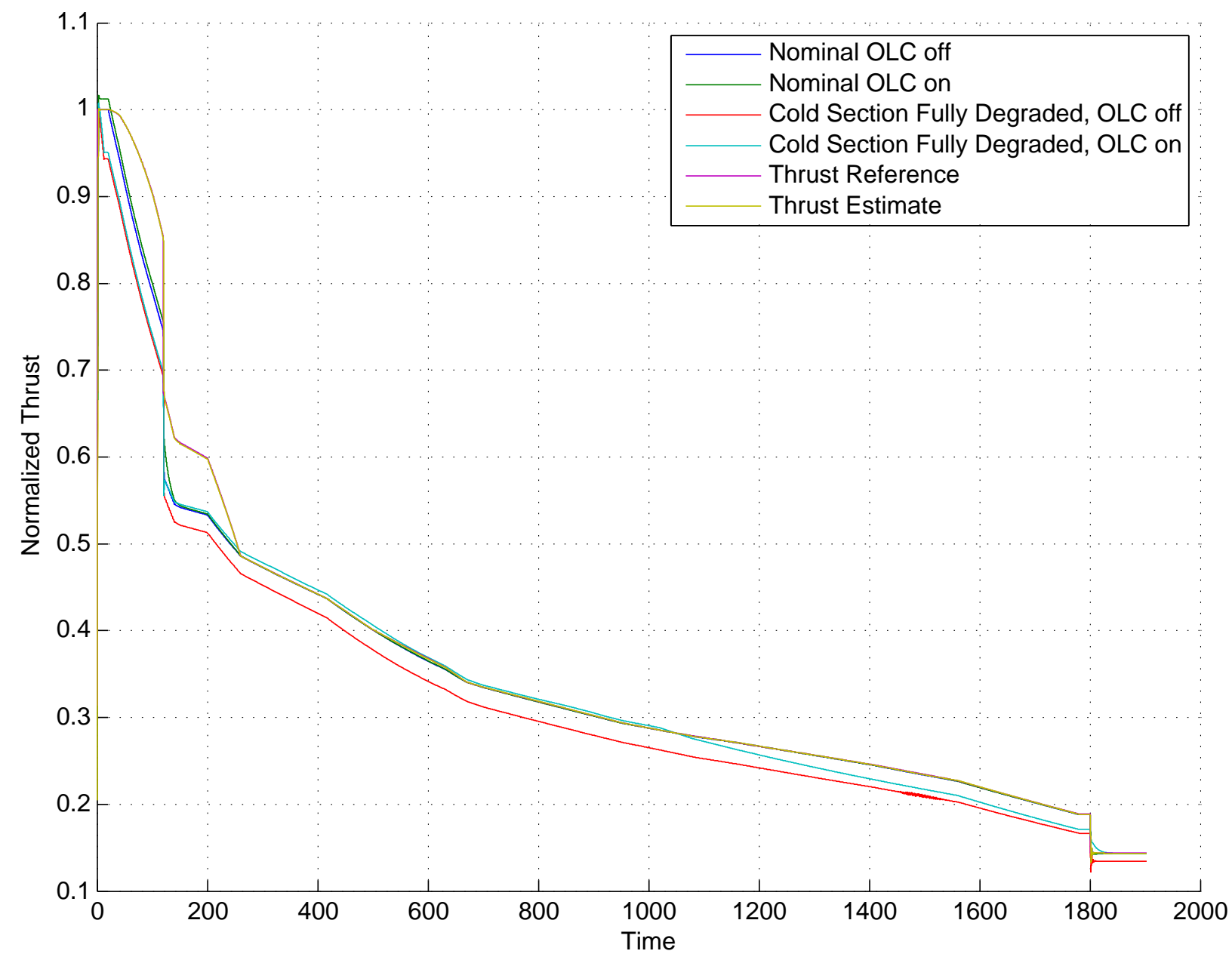

Figure 9. Take-off transient thrust response and estimate with OLC on and off for worst case cold section deterioration, plus nominal engine response. 


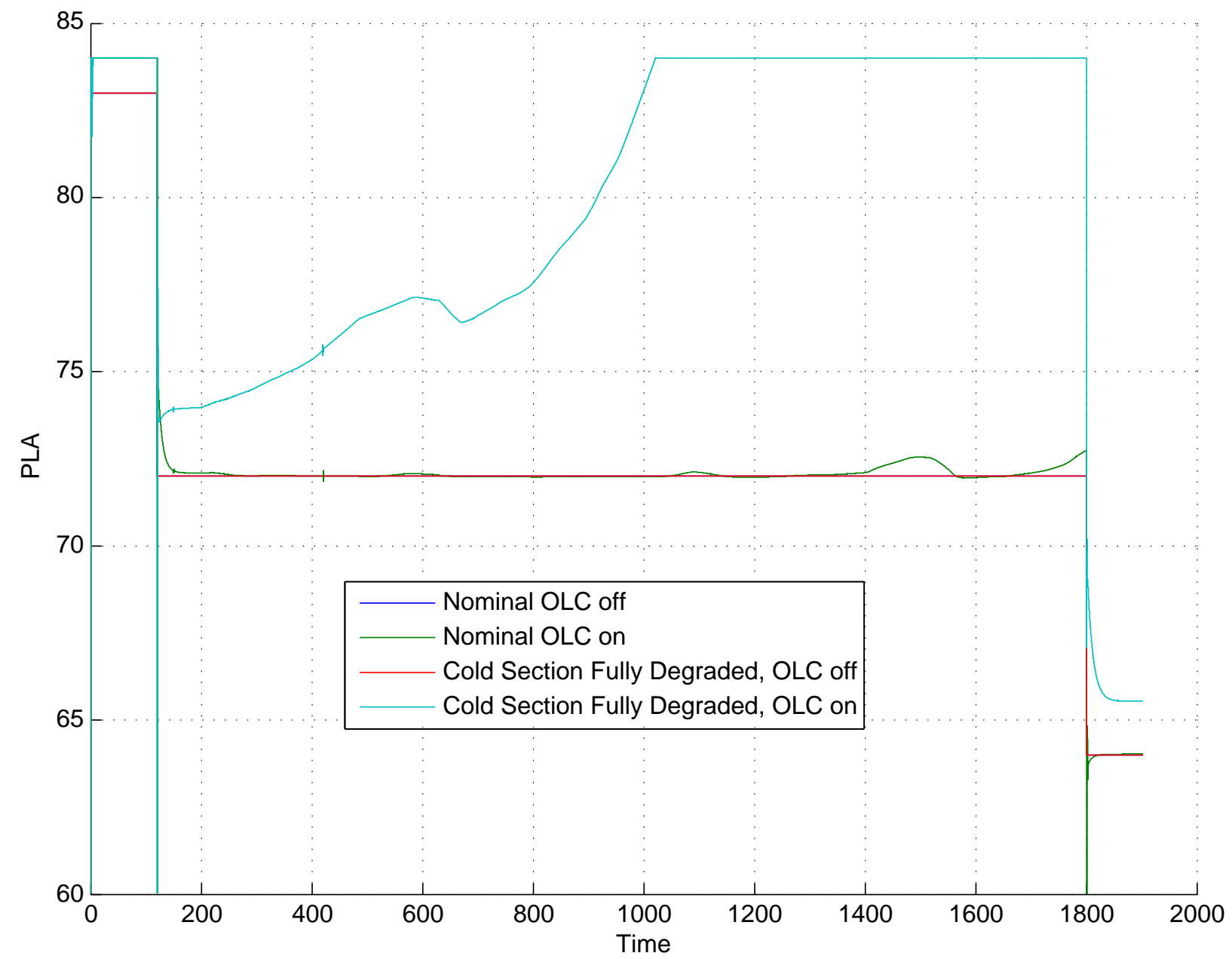

Figure 10. Take-off transient PLA input plus $\triangle P L A$ with OLC on and off for worst case cold section deterioration. 


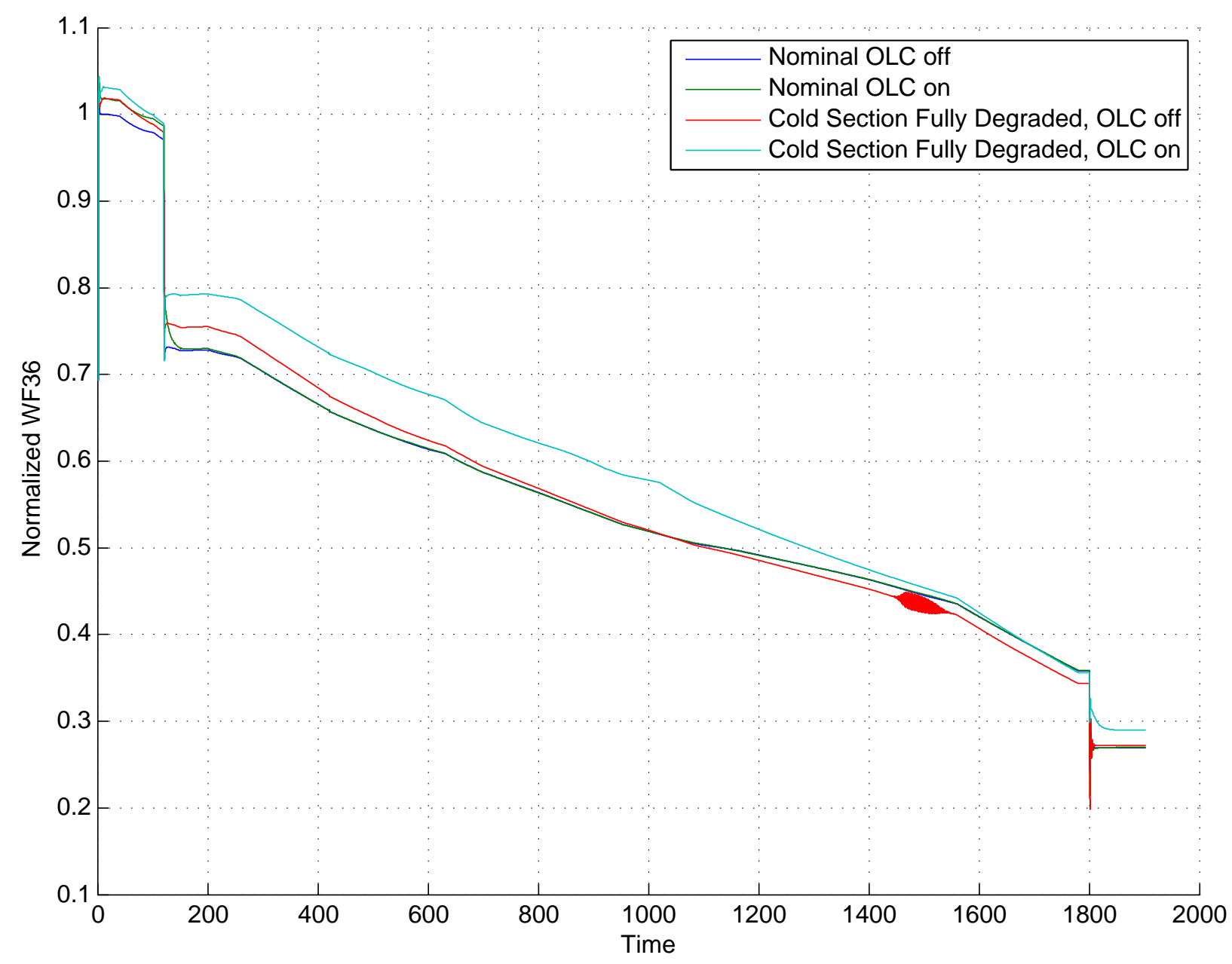

Figure 11. Take-off transient fuel flow with OLC on and off for worst cold section deterioration. 


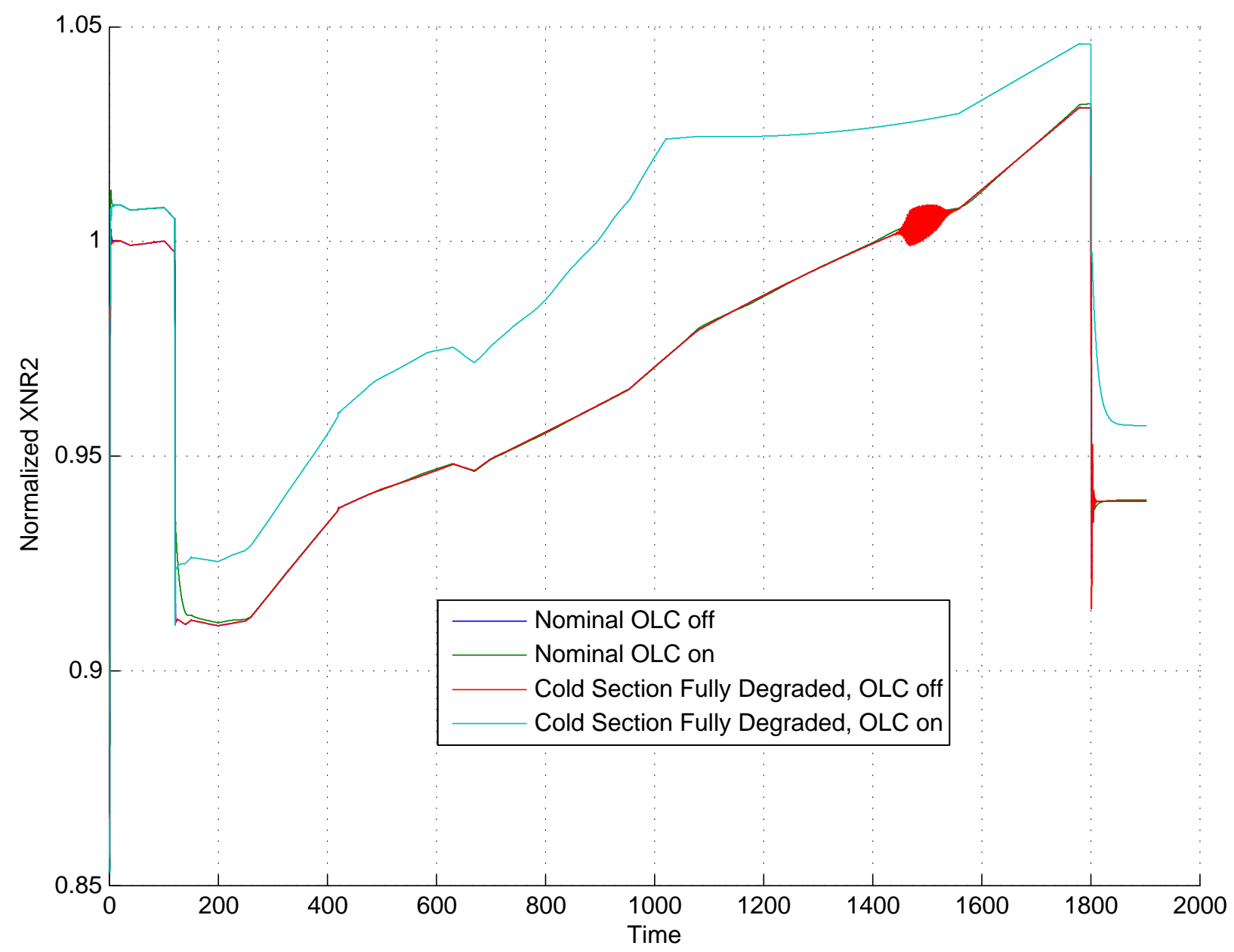

Figure 12. Take-off transient normalized Percent Corrected Fan Speed with OLC on and off for worst case cold section deterioration. 


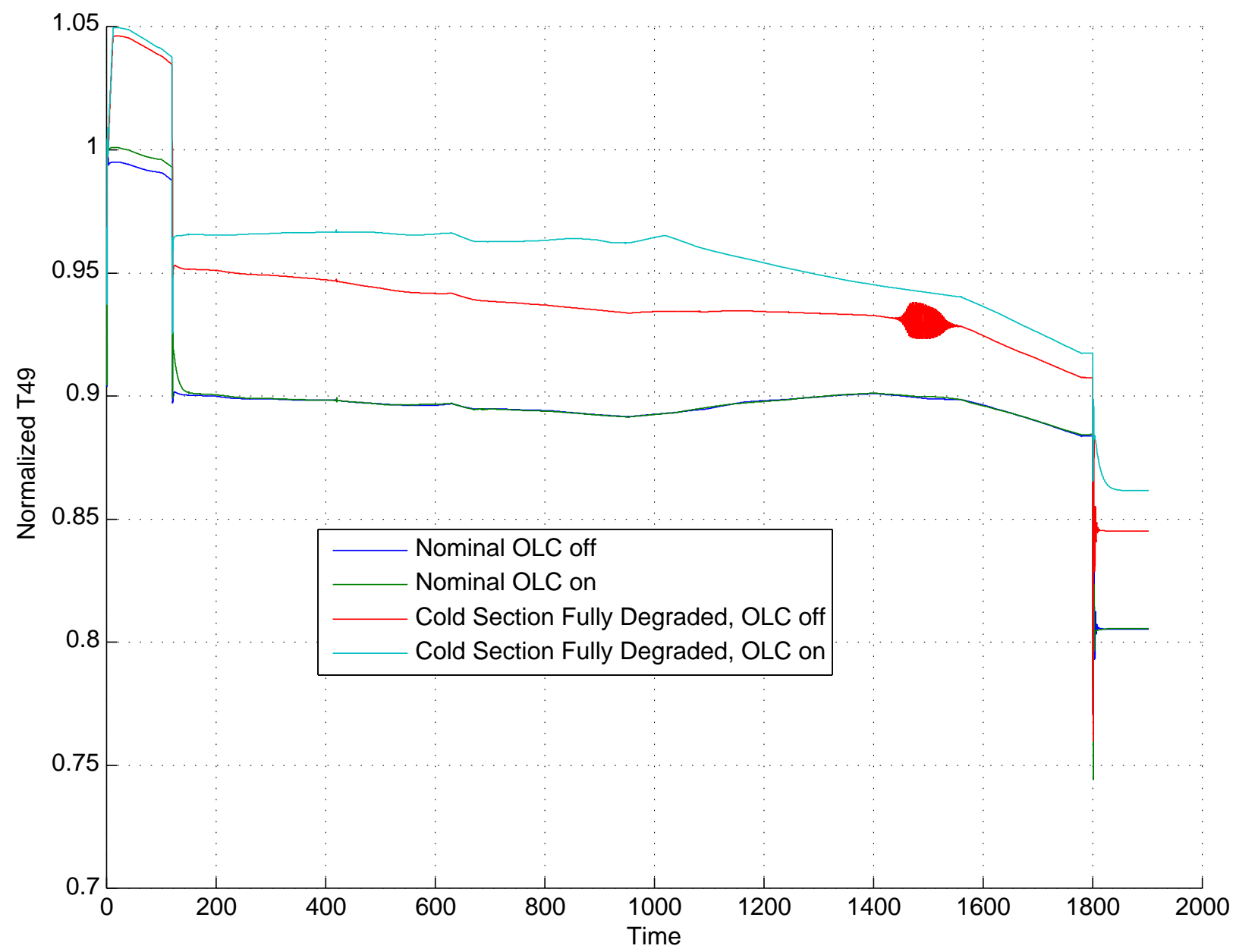

Figure 13. Take-off transient Exhaust Gas Temperature with OLC on and off for worst case cold section deterioration. 


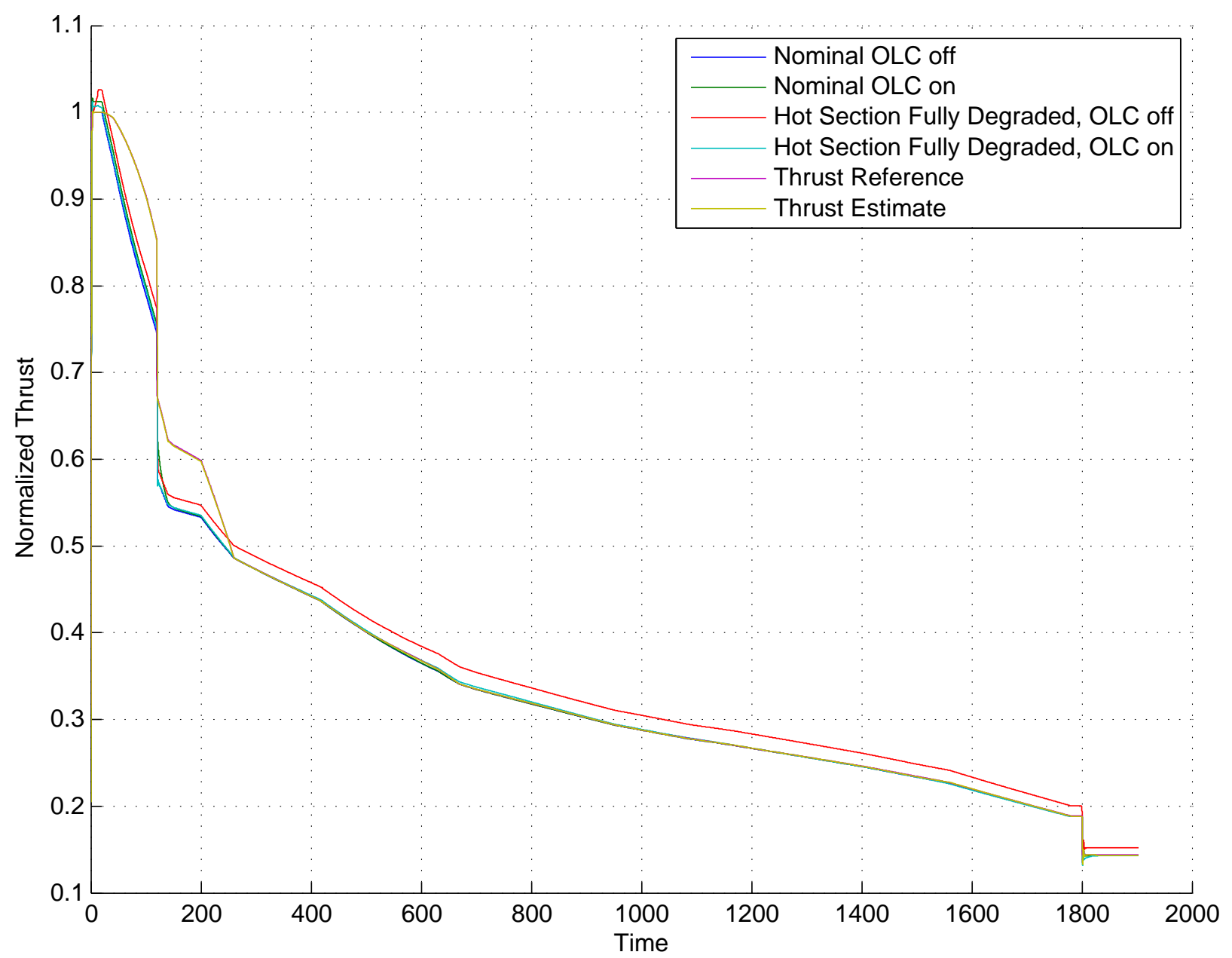

Figure 14. Take-off transient thrust response and estimate with OLC on and off for worst case hot section deterioration, plus nominal engine response. 


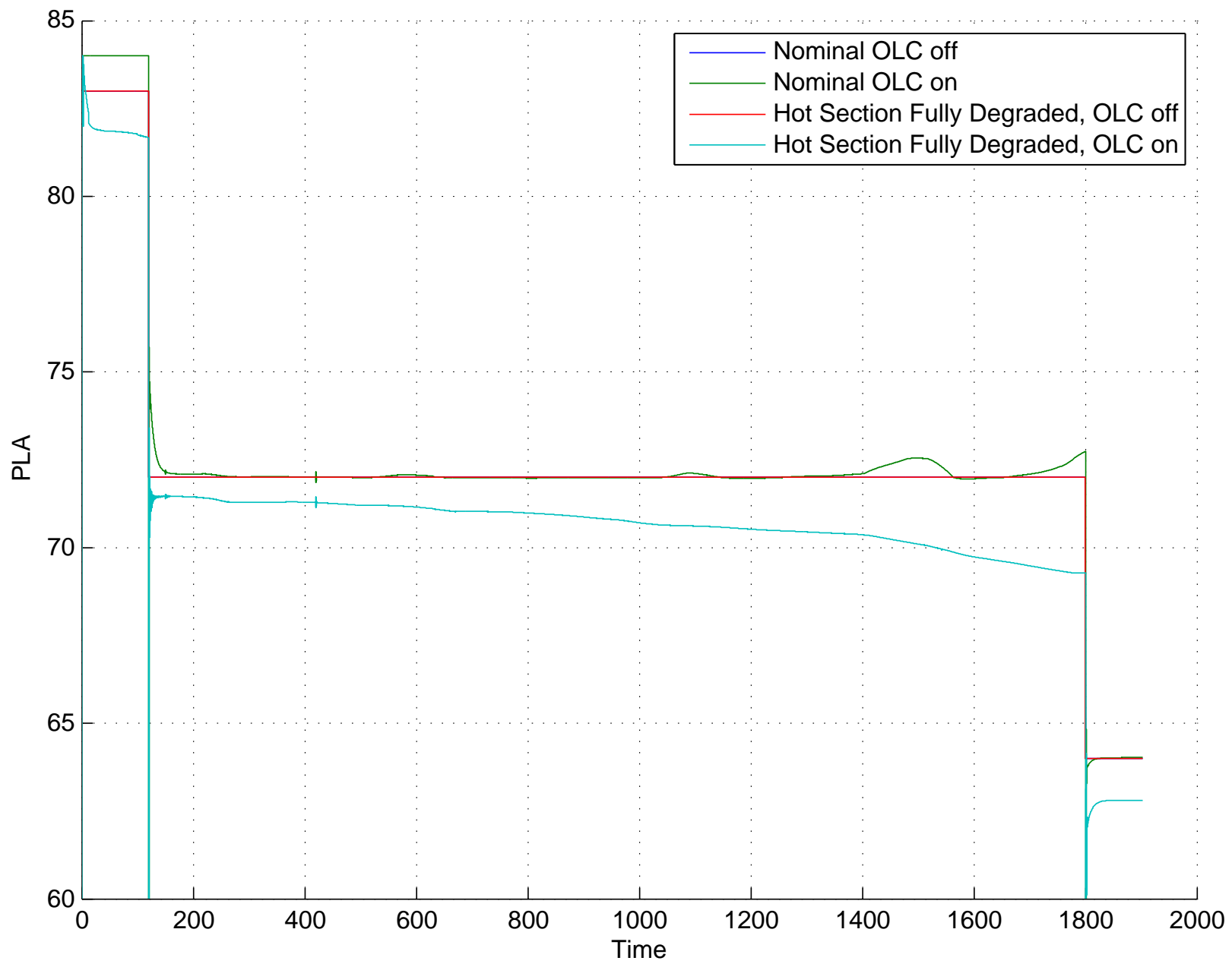

Figure 15. Take-off transient PLA input plus $\triangle$ PLA with OLC on and off for worst case hot section deterioration. 


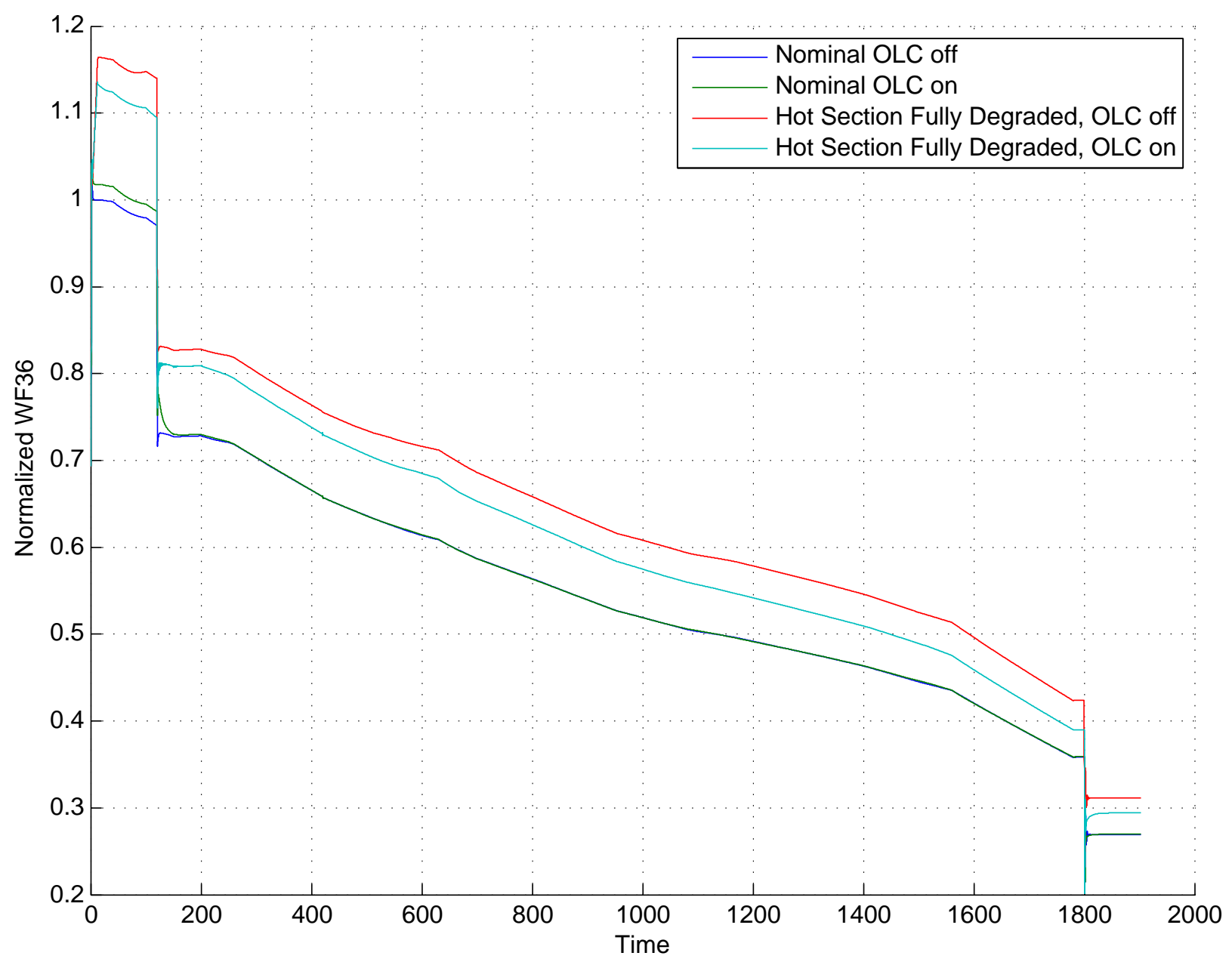

Figure 16. Take-off transient fuel flow with OLC on and off for worst case hot section deterioration. 


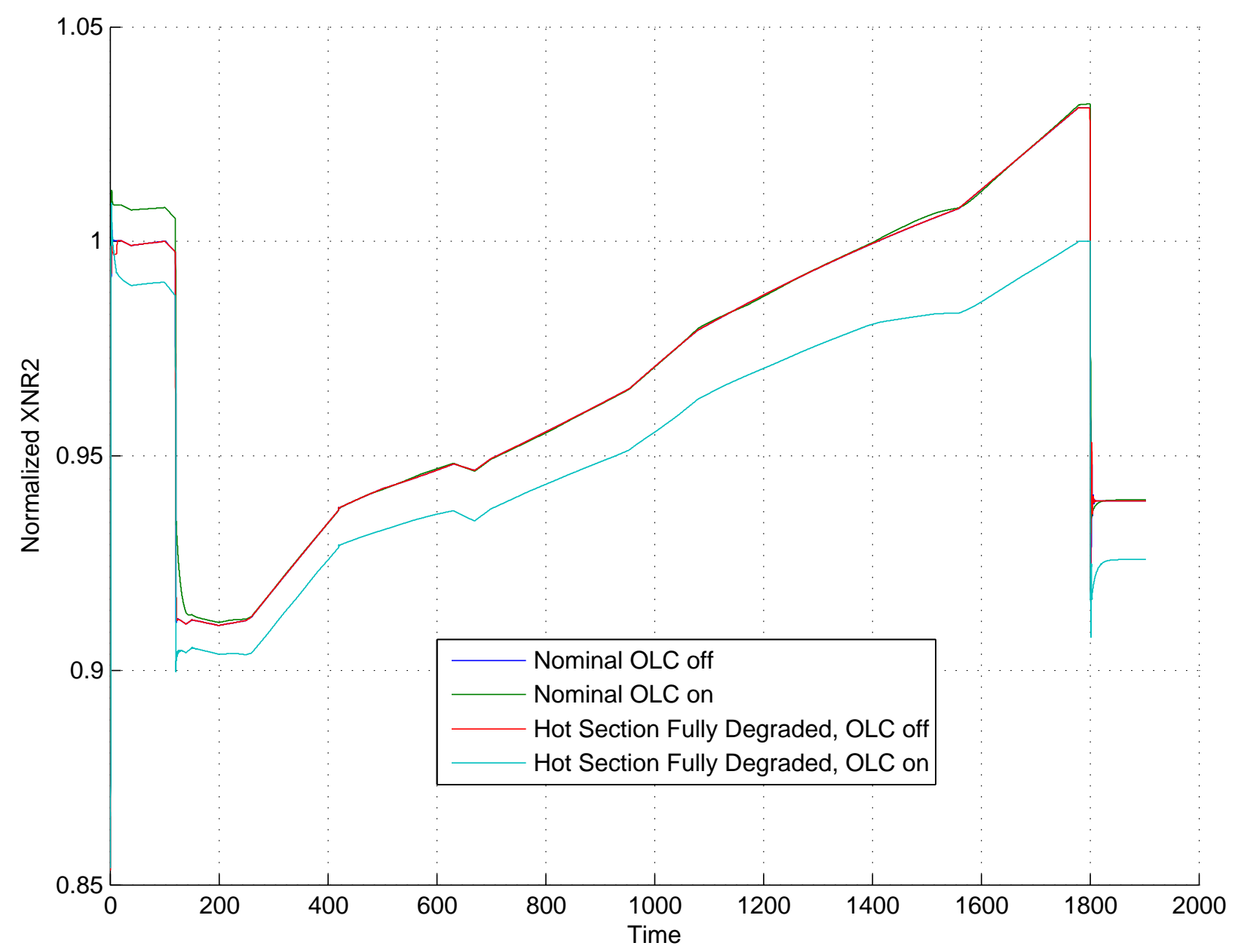

Figure 17. Take-off transient normalized Percent Corrected Fan Speed with OLC on and off for worst case hot section deterioration. 


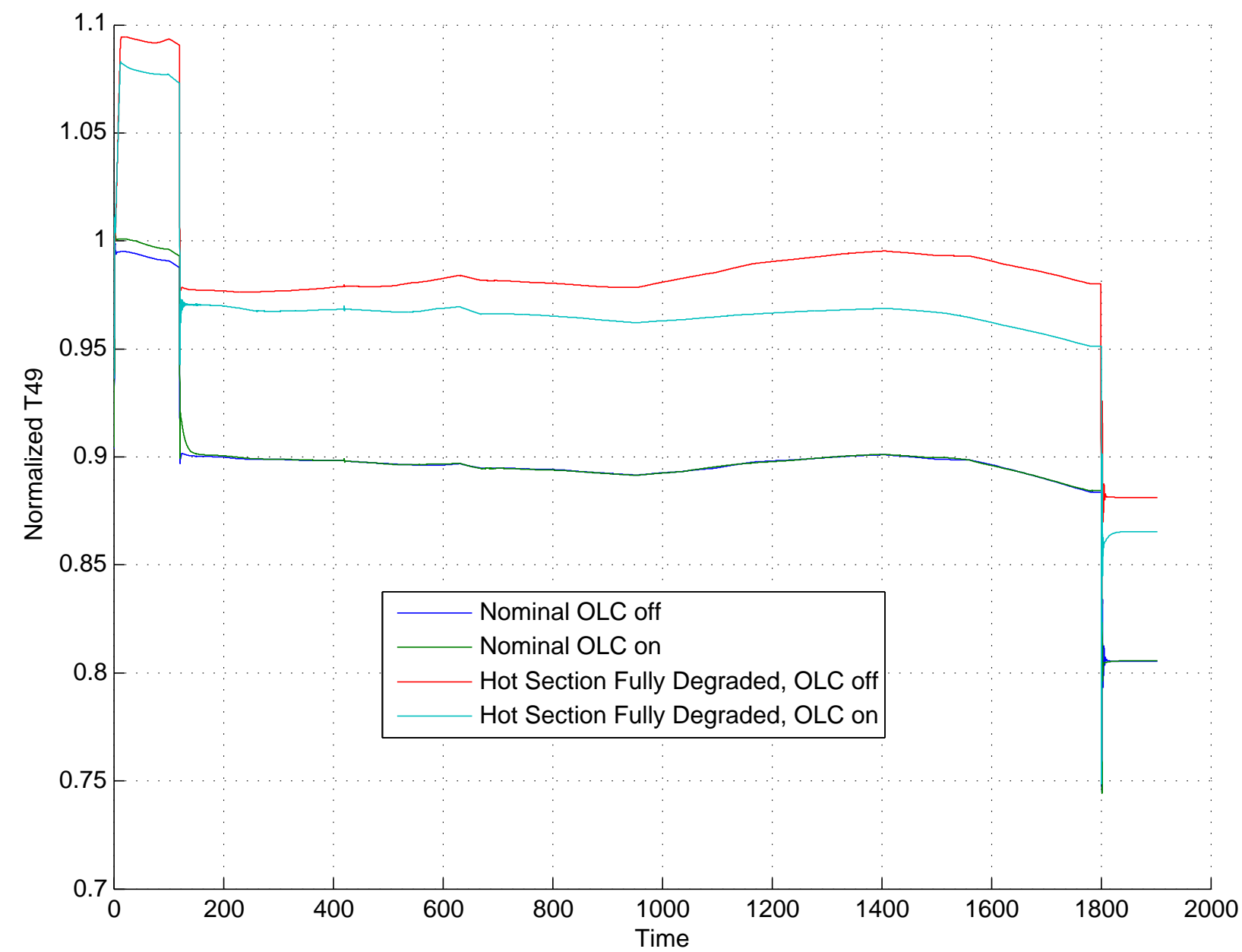

Figure 18. Take-off transient Exhaust Gas Temperature with OLC on and off for worst case hot section deterioration. 


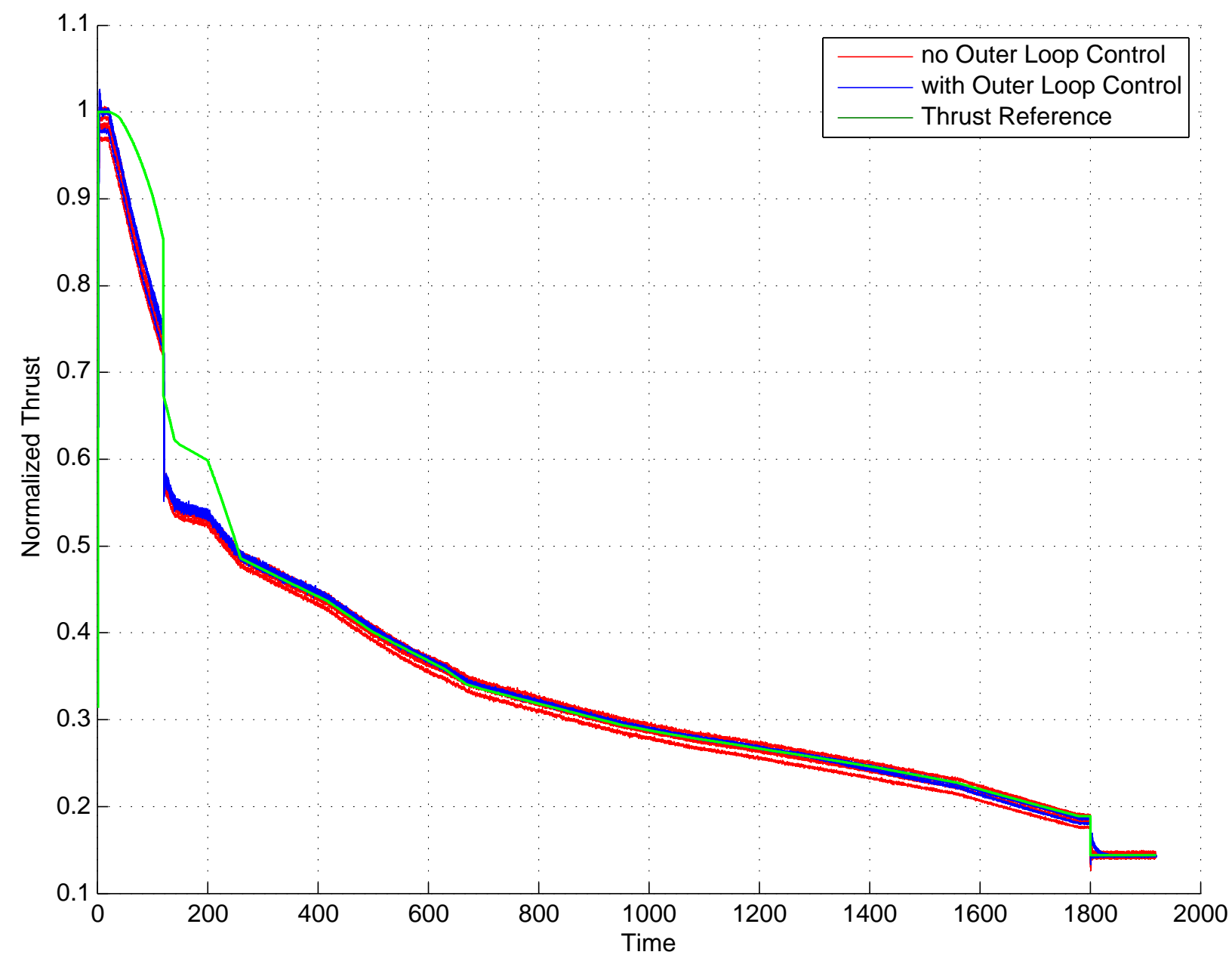

Figure 19. Take-off thrust responses for randomly deteriorated engines with OLC on and off, plus outer loop thrust reference. 


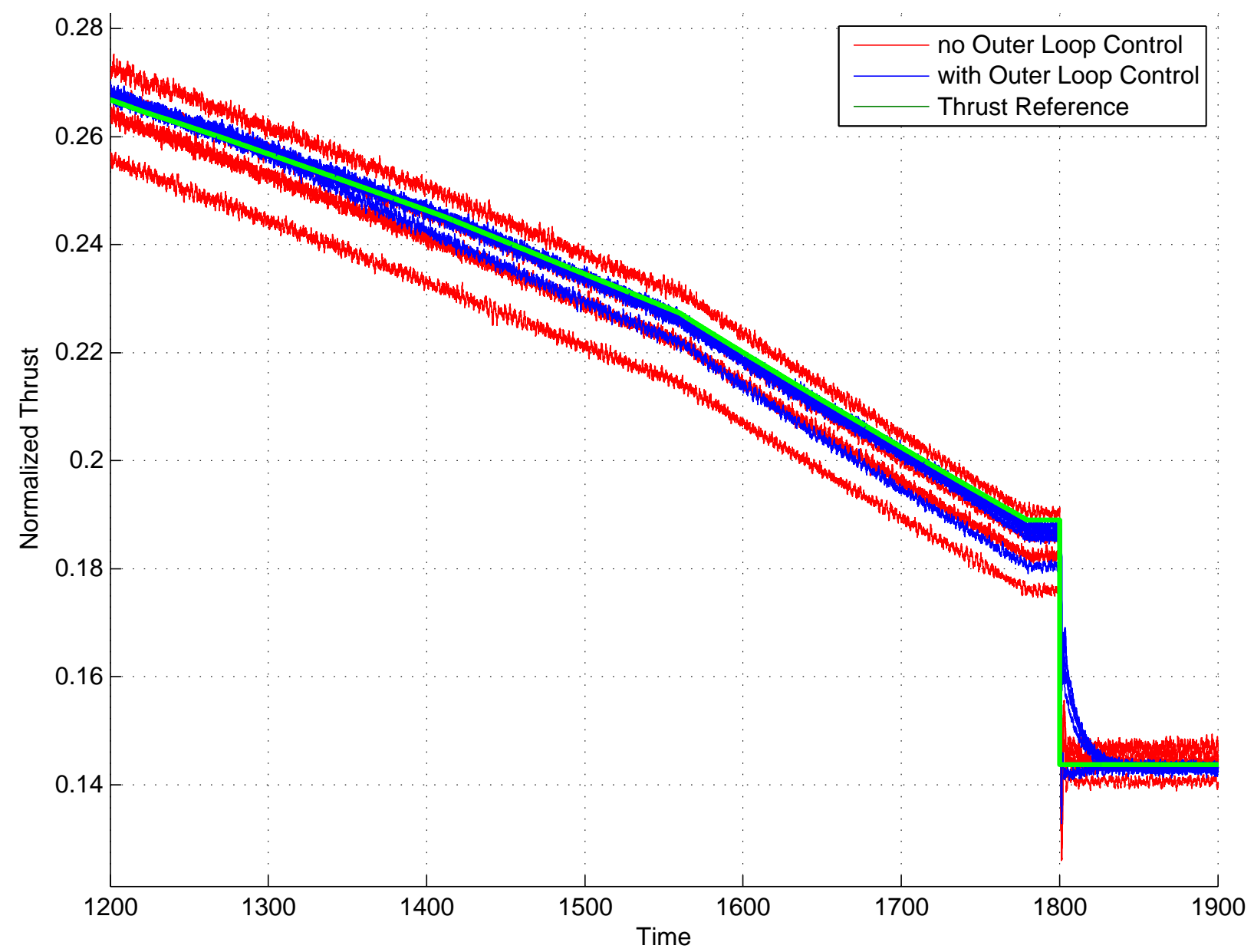

Figure 20. Detail of Figure 19 (thrust responses for randomly deteriorated engines with OLC on and off, plus outer loop thrust reference). 


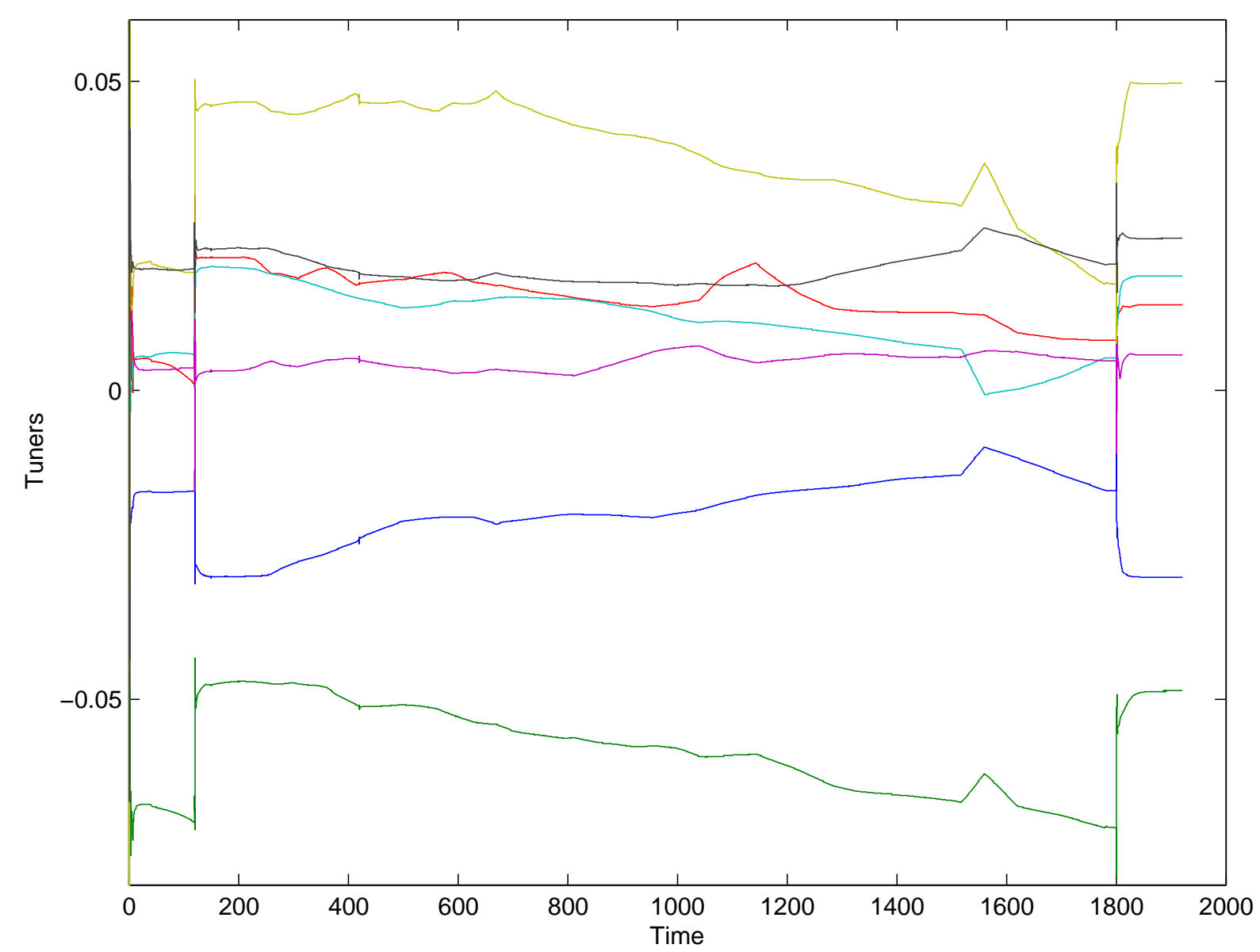

Figure 21. The seven tuners through the take-off transient of a degraded engine (noise-free).

\section{Discussion}

The process of degradation is gradual and in general the outer loop compensation will not be noticeable. In cases where the physical limit of the engine was not reached, the outer loop control is able to recover the nominal thrust. In degradation cases that result in reduced thrust, the outer loop control will probably saturate PLA during take-off when demand is high, but in a full implementation of the hierarchical architecture on a multi-engine aircraft (which is not considered here) the thrust setpoint logic should be able to maintain thrust at an appropriate level so that a yawing moment is not introduced, i.e. it might reduce the thrust demand slightly. However, most of the time deterioration results in increased thrust and EGT, so outer loop thrust control can provide a benefit at takeoff when temperature minimization is most important and at cruise when fuel consumption is most important.

The outer loop adjustment of PLA with a maximum PLA limit produces an unnecessarily conservative thrust controller. The examples of thrust error due to PLA saturation could potentially be reduced or eliminated if the fan speed command inside the FADEC were directly adjusted, especially if the fan speed limit is higher than what maximum PLA represents. Since fan speed is actually the variable that corresponds to thrust output, limiting PLA can result in a fan speed command that is too low, thus producing less than the desired thrust, even though the controller itself is not hitting a limit. If the retrofit architecture were to be implemented within the FADEC, leaving the existing control logic untouched, it makes sense for the outer loop to increment fan speed rather than PLA, as long as the resulting total fan speed demand still passes through the limit logic.

The thrust estimator can be tuned in two ways which may have an impact on accuracy. First, the design procedure allows for the incorporation of weights on specific variables, ${ }^{5}$ which can improve the estimation of some variables at the expense of others. No non-unity weights were used in the example given here, but experimentation with weights might have resulted in even better results. The second major design approach involves the use of a common right factor, $V^{*}$, and thus a common tuning vector $q$ at all operating points; the alternative is to perform SVD at each linearization point individually, which might provide better approximation by the reduced order model 
at each point. However, the approach used specifically avoids discontinuities that might occur in the estimation of $q$ as the engine moves between operating points, since the system matrices at individual operating points may have significantly different singular values.

A standard, operating point-independent tuning vector $q$ was derived for use here, as a result of the common $V^{*}$ matrix in eq. (3). An idealized tuning vector, one which is insensitive to operating point, can potentially provide a significant benefit for diagnostics because it should only be sensitive to degradation and faults. ${ }^{12}$ Figure 21 shows the tuners for a single degraded case of a full take-off transient simulation, and it is clear that they are not constant across the flight envelope, and are also affected by PLA movements. This result seems to indicate that, if it is possible to obtain tuners that are consistent across the flight envelope, more work is needed to develop them.

\section{Conclusions}

Essential to the implementation of an intelligent retrofit turbine engine control and diagnostics architecture (Figure 3), which was designed to reduce pilot workload, is the thrust estimator and outer loop thrust control. This paper describes a real-time implementation of this portion of the architecture in simulation, which was evaluated for robustness to the types of uncertainties that would be encountered in a real implementation. It was shown to work well in all cases evaluated, up to the physical limits of the engine. The accuracy of the thrust estimation was good, with the maximum mean estimation error of about $1.6 \%$ of nominal for the operating point. Using the thrust estimate for feedback produced much tighter regulation of thrust than indirect control through fan speed. The incremental control commands added by the system enter the FADEC and as such are still subject to the controller's limit logic, preventing any undesigned-for operation of the engine. Examples showed, however, that incrementing PLA into the controller rather than fan speed command within the controller led to conservative performance and potential thrust error; direct fan speed command adjustment should be investigated in future work. Because of the success in regulating thrust over a wide operating range under a variety of deterioration conditions, it appears that a full implementation of such an architecture is a viable approach for this application. The architecture greatly increases the autonomy of the propulsion system, and thus enables the concept of an Intelligent Flight Control/Mission Manager.

\section{References}

${ }^{1}$ Litt, J. S., et al., "A Survey of Intelligent Control and Health Management Technologies for Aircraft Propulsion Systems," Journal of Aerospace Computing, Information, and Communication [online journal], Vol. 1, No. 12, December 2004, pp. 543563, URL: www.aiaa.org/jacicl, [cited 2 September 2005].

${ }^{2}$ Litt, J. S., Turso, J. A., Shah, N., Sowers, T. S., and Owen, A. K., "A Demonstration of a Retrofit Architecture for Intelligent Control and Diagnostics of a Turbofan Engine,” Infotech@ Aerospace, Arlington, VA, 26-29 Sept, 2005.

${ }^{3}$ Martucci, A., and Volponi, A.J., "Fuzzy Fuel Flow Selection Logic for a Real Time Embedded Full Authority Digital Engine Control," Journal of Engineering for Gas Turbines and Power, Vol. 125, Oct. 2003, pp. 909-916.

${ }^{4}$ Bosco, C. J., "Certification Issues For Electrical and/or Electronic Engine Controls," SAE Paper 871844, Aerospace Technology Conference and Exposition, Long Beach, CA, Oct. 5-8, 1987.

${ }^{5}$ Litt, J. S., "An Optimal Orthogonal Decomposition Method for Kalman Filter-Based Turbofan Engine Thrust Estimation," GT2005-68808, Proceedings of the 2005 ASME Turbo Expo, Reno-Tahoe, NV, June 6-9, 2005.

${ }^{6}$ Volponi, A. J., "Gas Turbine Parameter Corrections," Journal of Engineering for Gas Turbines and Power, Vol. 121, October 1999, pp. 613-621.

${ }^{7}$ Kurzke, J., "Model Based Gas Turbine Parameter Corrections," GT203-38234, Proceedings of 2003 ASME Turbo Expo, June 16-19, 2003.

${ }^{8}$ Kobayashi, T., Simon, D. L., "Evaluation of an Enhanced Bank of Kalman Filters for In-Flight Aircraft Engine Sensor Fault Diagnostics," Journal of Engineering for Gas Turbines and Power, Vol. 127, July 2005, pp. 497-504.

${ }^{9}$ Astrom, K. A., Hagglund, T., PID Controllers: Theory, Design, and Tuning, $2^{\text {nd }}$, Instrument Society of America, Research Triangle Park, NC, 1995, pp. 88-91.

${ }^{10}$ The Aircraft Gas Turbine Engine and its Operation, Part No. PWA 182408, PWA Oper. Instr. 200, United Technologies Corporation, Reprinted with revisions August 1988.

${ }^{11}$ Brunell, B. J., Viassolo, D. E., and Prasanth, R., "Model Adaptation and Nonlinear Model Predictive Control of an Aircraft Engine," GT-2004-53780, Proceedings of the 2004 ASME Turbo Expo, Vienna, Austria, 2004.

${ }^{12}$ Brotherton, T., Volponi, A., Luppold, R., and Simon, D.L., "eSTORM: Enhanced Self Tuning On-board Real-time Engine

Model," Proceedings of the 2003 IEEE Aerospace Conference, Big Sky, MT, March 8-15, 2003. 


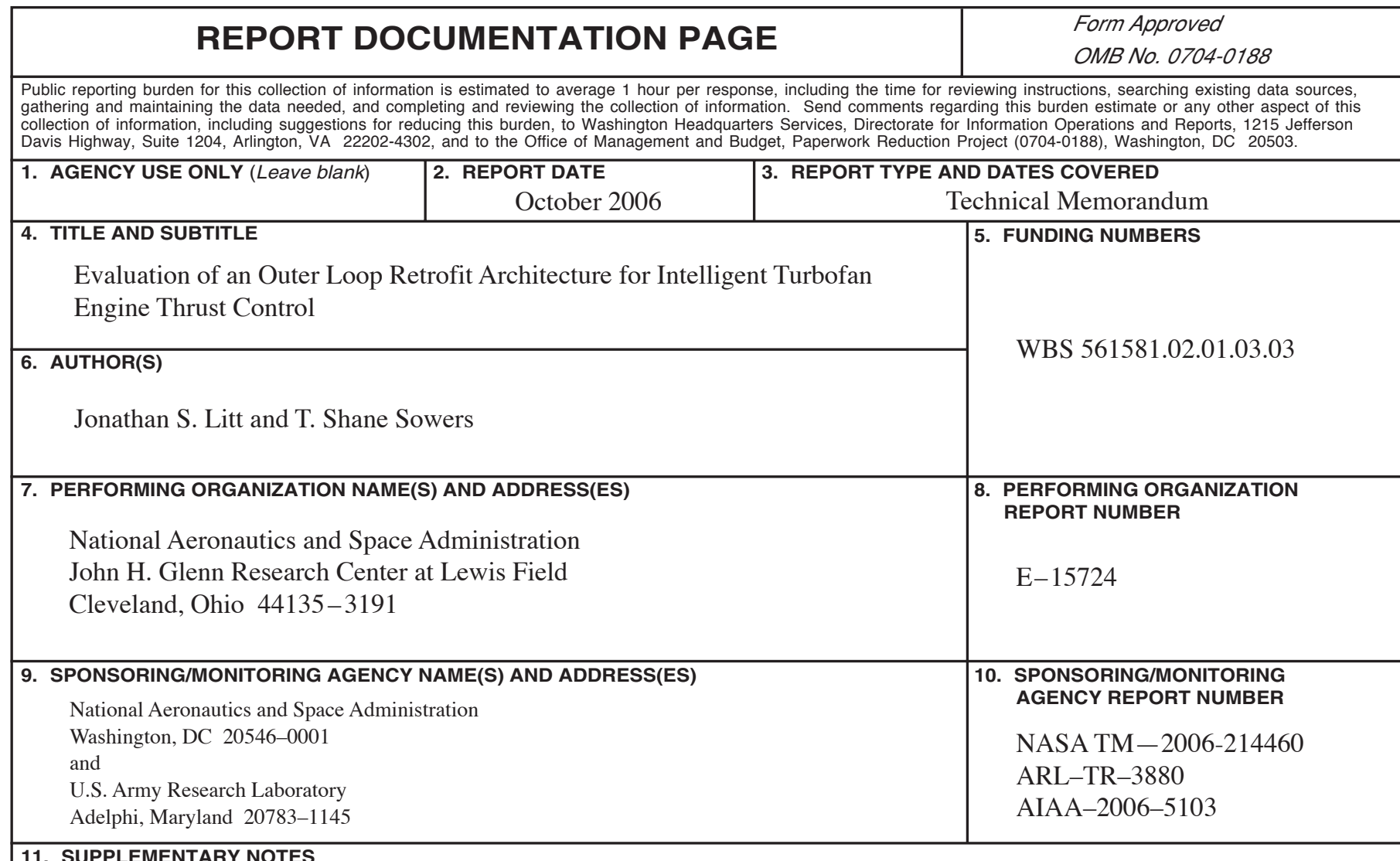

\section{SUPPLEMENTARY NOTES}

Prepared for the 42nd Joint Propulsion Conference and Exhibit cosponsored by the AIAA, ASME, SAE, and ASEE, Sacramento, California, July 9-12, 2006. Jonathan S. Litt, U.S. Army Research Laboratory, NASA Glenn Research Center; and T. Shane Sowers, Analex Corporation, 1100 Apollo Drive, Brook Park, Ohio 44142. Responsible person, Jonathan S. Litt, organization code Z, 216-433-3748.

12a. DISTRIBUTION/AVAILABILITY STATEMENT 12b. DISTRIBUTION CODE

Unclassified - Unlimited

Subject Categories: 07, 08, 63

Available electronically at http://gltrs.grc.nasa.gov

This publication is available from the NASA Center for AeroSpace Information, 301-621-0390.

13. ABSTRACT (Maximum 200 words)

The thrust control capability of a retrofit architecture for intelligent turbofan engine control and diagnostics is evaluated. The focus of the study is on the portion of the hierarchical architecture that performs thrust estimation and outer loop thrust control. The inner loop controls fan speed so the outer loop automatically adjusts the engine's fan speed command to maintain thrust at the desired level, based on pilot input, even as the engine deteriorates with use. The thrust estimation accuracy is assessed under nominal and deteriorated conditions at multiple operating points, and the closed loop thrust control performance is studied, all in a complex real-time nonlinear turbofan engine simulation test bed. The estimation capability, thrust response, and robustness to uncertainty in the form of engine degradation are evaluated.

14. SUBJECT TERMS

15. NUMBER OF PAGES

Propulsion control; Diagnostics; Artificial intelligence 33

\begin{tabular}{|c|c|}
\hline $\begin{array}{c}\text { 17. SECURITY CLASSIFICATION } \\
\text { OF REPORT }\end{array}$ & $\begin{array}{c}\text { 18. SECURITY CLASSIFICATION } \\
\text { OF THIS PAGE } \\
\text { Unclassified }\end{array}$ \\
Unclassified \\
\hline
\end{tabular}



